\title{
Tropospheric nitrogen dioxide column retrieval from ground-based zenith-sky DOAS observations
}

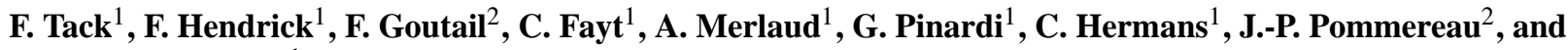 \\ M. Van Roozendael ${ }^{1}$ \\ ${ }^{1}$ BIRA-IASB, Belgian Institute for Space Aeronomy, Brussels, Belgium \\ ${ }^{2}$ LATMOS, Laboratoire Atmosphères, Milieux, Observations Spatiales, Guyancourt, France
}

Correspondence to: F. Tack (frederik.tack@aeronomie.be)

Received: 22 December 2014 - Published in Atmos. Meas. Tech. Discuss.: 26 January 2015

Revised: 6 May 2015 - Accepted: 7 May 2015 - Published: 10 June 2015

\begin{abstract}
We present an algorithm for retrieving tropospheric nitrogen dioxide $\left(\mathrm{NO}_{2}\right)$ vertical column densities (VCDs) from ground-based zenith-sky (ZS) measurements of scattered sunlight. The method is based on a four-step approach consisting of (1) the differential optical absorption spectroscopy (DOAS) analysis of ZS radiance spectra using a fixed reference spectrum corresponding to low $\mathrm{NO}_{2}$ absorption, (2) the determination of the residual amount in the reference spectrum using a Langley-plot-type method, (3) the removal of the stratospheric content from the daytime total measured slant column based on stratospheric VCDs measured at sunrise and sunset, and simulation of the rapid $\mathrm{NO}_{2}$ diurnal variation, (4) the retrieval of tropospheric VCDs by dividing the resulting tropospheric slant columns by appropriate air mass factors (AMFs). These steps are fully characterized and recommendations are given for each of them. The retrieval algorithm is applied on a ZS data set acquired with a multi-axis (MAX-) DOAS instrument during the Cabauw $\left(51.97^{\circ} \mathrm{N}, 4.93^{\circ} \mathrm{E}\right.$, sea level) Intercomparison campaign for Nitrogen Dioxide measuring Instruments (CINDI) held from 10 June to 21 July 2009 in the Netherlands. A median value of $7.9 \times 10^{15} \mathrm{molec}^{-2}$ is found for the retrieved tropospheric $\mathrm{NO}_{2}$ VCDs, with maxima up to $6.0 \times 10^{16}$ molec $\mathrm{cm}^{-2}$. The error budget assessment indicates that the overall error $\sigma_{\mathrm{TVCD}}$ on the column values is less than $28 \%$. In the case of low tropospheric contribution, $\sigma_{\mathrm{TVCD}}$ is estimated to be around $39 \%$ and is dominated by uncertainties in the determination of the residual amount in the reference spectrum. For strong tropospheric pollution events, $\sigma_{\mathrm{TVCD}}$ drops to approximately $22 \%$ with the largest uncertainties on the determination of the strato-
\end{abstract}

spheric $\mathrm{NO}_{2}$ abundance and tropospheric AMFs. The tropospheric VCD amounts derived from ZS observations are compared to VCDs retrieved from off-axis and direct-sun measurements of the same MAX-DOAS instrument as well as to data from a co-located Système d'Analyse par Observations Zénithales (SAOZ) spectrometer. The retrieved tropospheric VCDs are in good agreement with the different data sets with correlation coefficients and slopes close to or larger than 0.9. The potential of the presented ZS retrieval algorithm is further demonstrated by its successful application on a 2-year data set, acquired at the NDACC (Network for the Detection of Atmospheric Composition Change) station Observatoire de Haute Provence (OHP; Southern France).

\section{Introduction}

Nitrogen dioxide $\left(\mathrm{NO}_{2}\right)$ is an atmospheric trace gas that plays a major role in atmospheric chemistry (Crutzen, 1979). In the troposphere, it is a key precursor in the formation of ozone (Crutzen, 1970) and aerosols (Chan et al., 2010), and can contribute locally to radiative forcing (Solomon et al., 1999), through which it indirectly affects the climate system. As tropospheric $\mathrm{NO}_{2}$ abundances mostly coincide with a range of other pollutants it can be seen as a proxy for air pollution in general. According to a recent study on air pollution published by the World Health Organization (WHO, 2013), $\mathrm{NO}_{2}$ can have a direct impact on human health, causing inflammation, airway hyperresponsiveness and lung cell changes in the short term and respiratory and cardiovascular mortality in the long term. Main sources of tropospheric 
$\mathrm{NO}_{2}$ can be of anthropogenic origin (e.g. industrial burning processes and fossil fuel combustion) and natural origin (e.g. lightning and soil emissions). Tropospheric $\mathrm{NO}_{2}$ concentrations can be highly variable in time and space in polluted regions. For the reasons stated, the long-term and accurate monitoring of this trace gas is of great relevance.

Here, we present a retrieval algorithm developed at BIRAIASB (Belgian Institute for Space Aeronomy) for deriving tropospheric $\mathrm{NO}_{2}$ vertical column densities (VCDs) from ground-based (GB) zenith-sky (ZS) observations of scattered sunlight by application of the differential optical absorption spectroscopy (DOAS) technique. DOAS is a wellestablished remote sensing technique that is able to quantify the abundance of trace gases like $\mathrm{NO}_{2}$ in the atmosphere, based on their unique spectral signature (Platt and Stutz, 2008). The main principles of the DOAS technique are (1) to separate the trace gas fine-scale absorption features from broad-band absorption due to scattering effects (mainly Rayleigh and Mie scattering), (2) to analyse the remaining absorber narrow-band structures by least-squares spectral fitting on laboratory cross-sections. The mathematical and physical fundamentals of the method are extensively described in Platt (1994), and Platt and Stutz (2008). DOAS instruments typically operate in the ultraviolet (UV) and visible (Vis) channels of the solar spectrum. In the case of the GB ZS-DOAS setup, an optical head, connected to a spectrometer coupled to a charge-coupled device (CCD) detector, points permanently to the zenith. This setup exploits the diurnal variation of the solar zenith angle (SZA).

Many studies can be found in the literature discussing the application of the DOAS method for determination of $\mathrm{NO}_{2}$ column abundances in the atmosphere based on observations from ground-based, airborne and spaceborne platforms. Without the intention to be complete, an overview of some relevant studies is provided here. The pioneering works of Brewer et al. (1973) and Noxon (1975) report on observations of $\mathrm{NO}_{2}$ concentrations in the atmosphere based on GB ZS measurements. For more than 3 decades, these measurements have been commonly performed to monitor trace gases related to the ozone depletion in the stratosphere, such as $\mathrm{NO}_{2}$ (e.g. Solomon et al., 1987; McKenzie et al., 1991, Goutail et al., 1994; Hendrick et al., 2004; Denis et al., 2005). More recently, GB Multi-Axis DOAS (MAXDOAS) has proven to be a suitable and reliable approach to retrieve integrated column amounts of tropospheric trace gases as well as information on their vertical distribution (e.g. Hönninger et al., 2004; Wittrock et al., 2004; Frieß et al., 2006; Clémer et al., 2010; Vlemmix et al., 2011; Wagner et al., 2011; Hendrick et al., 2014). In addition to ZS observations, the GB MAX-DOAS setup measures scattered sunlight from multiple viewing angles towards the horizon (the so-called off-axis geometry), increasing, therefore, the sensitivity to absorbers present close to the ground, because of the longer light paths through the lower troposphere. The DOAS method is also applied to assess total and tropo- spheric $\mathrm{NO}_{2}$ columns from nadir-viewing spaceborne sensors like SCIAMACHY (scanning imaging absorption chartography), GOME (Global Ozone Monitoring Experiment), GOME-2, and OMI (Ozone Monitoring Experiment) (see e.g. Richter and Burrows, 2002; Beirle et al., 2010; Boersma et al., 2011; Valks et al., 2011; Bucsela et al., 2013; Hilboll et al., 2013). Other experiments have been published, presenting approaches to monitor tropospheric $\mathrm{NO}_{2}$ from car (Johansson et al., 2009; Wagner et al., 2010; Constantin et al., 2013) and airborne platforms (Berg et al., 2012; Merlaud et al., 2012; Popp et al., 2012).

Here we describe the different steps of a new ZS retrieval algorithm for tropospheric $\mathrm{NO}_{2}$ columns. The limitations and possible alternatives for this method are additionally discussed. The sensitivity of MAX-DOAS observations to the lower troposphere is larger when compared to ZS-DOAS observations, and therefore it is generally considered as a more suitable technique for tropospheric $\mathrm{NO}_{2}$ retrieval. However, the major merit of the ZS-DOAS approach in comparison to MAX-DOAS relates to the fact that a large number of historical stations, e.g. within NDACC (Network for the Detection of Atmospheric Composition Change), are equipped with instruments that only perform zenith observations. For these stations, the proposed algorithm offers possibilities for tropospheric trace gas retrieval, in addition to the more common stratospheric monitoring. Furthermore, applied to historical decadal time series of observations (as available at some stations of the NDACC), the proposed algorithm would enable to document the long-term variability of tropospheric $\mathrm{NO}_{2}$ in addition to stratospheric $\mathrm{NO}_{2}$. On the other hand, the independent tropospheric $\mathrm{NO}_{2}$ estimates, retrieved by the presented ZS-DOAS algorithm, provide a way to evaluate MAX-DOAS retrievals at sites equipped with MAXDOAS instruments. So far, only a few studies have been published focusing on the retrieval of tropospheric $\mathrm{NO}_{2}$ column amounts solely based on GB ZS-DOAS observations. Chen et al. (2009) presented a retrieval algorithm, applied on ZS observations acquired in Shanghai (China). There are, however, a number of methodological differences with the approach presented here and these will be further discussed in this paper. In Dieudonné et al. (2013), a similar method is applied on ZS observations acquired in Paris (France). However, the retrieval strategy is discussed only very briefly as the focus of the latter publication is on linking retrieved tropospheric $\mathrm{NO}_{2}$ columns to surface concentrations.

The organization of this paper is as follows: Section 2 is dedicated to the description of the GB instrument used for the ZS observations, as well as the site where measurements were conducted. Section 3 describes the four main steps of the developed methodology for tropospheric $\mathrm{NO}_{2} \mathrm{VCD}$ retrieval from GB ZS-DOAS observations. Furthermore, the four steps of the retrieval approach are characterised in terms of an error budget analysis. Section 4 presents the retrieval results, including a comparison with correlative MAX-DOAS, direct sun (DS-) DOAS, and SAOZ (Système d'Analyse par 
Observations Zénithales) data. Section 5 discusses the retrieval approach with a focus on recommendations for application of the method on $\mathrm{ZS}$ observations at other stations. In Sect. 6 the application on observations acquired over 2 years at the NDACC site of Observatoire de Haute Provence (OHP; southern France) is demonstrated. The paper concludes with a brief summary.

\section{Ground-based DOAS observations}

The retrieval algorithm is first tested on a data set acquired from 10 June to 21 July 2009 by the BIRAIASB MAX-DOAS instrument, operated in the framework of the international Cabauw Intercomparison campaign for Nitrogen Dioxide measuring Instruments (CINDI). The CINDI campaign took place at Cabauw, The Netherlands $\left(51.97^{\circ} \mathrm{N}, 4.93^{\circ} \mathrm{E}\right.$, sea level) at the Cabauw Experimental Site for Atmospheric Research (CESAR; http://www. cesar-observatory.nl). It is located in a semi-rural area in the direct proximity of the four largest cities of the Netherlands (i.e. Amsterdam, Rotterdam, Den Haag and Utrecht). One of the main objectives of the campaign was to intercompare and inter-calibrate GB instruments measuring $\mathrm{NO}_{2}$ and determine their performance and accuracy. A more in-depth discussion of the CINDI campaign and results can be found in Roscoe et al. (2010) and Piters et al. (2012).

The BIRA-IASB MAX-DOAS instrument consists of three main parts. The optical head, mounted on a sun tracker (INTRA manufactured by Brusag), can collect the scattered sunlight over a wide range of elevation ( 0 to $90^{\circ}$ ) and azimuth angles (0 to $360^{\circ}$ ). Optical fibers guide the collected skylight from the output of the optical head to the spectrometers, the latter being placed in a thermoregulated container to guarantee high stability and minimise thermal stress. The dual-channel system is composed of a UV (ORIEL model MS260i; 1200 grooves $\mathrm{mm}^{-1}$ grating) and a visible (ORIEL model MS127; 600 grooves $\mathrm{mm}^{-1}$ ) grating spectrometer covering a wavelength range of 300390 and 400-720 nm, respectively. The Gaussian-shaped instrument's slit function, which was determined using a monochromatic emission light source $(\mathrm{HgCd})$, has a spectral resolution of $0.4 \mathrm{~nm}$ full width at half maximum (FWHM) and $0.9 \mathrm{~nm}$ FWHM for the UV and visible channels, respectively. Both spectrometers are connected to low-noise thermo-electrically cooled CCD detectors (Princeton Instruments, model PIXIS $2 \mathrm{KBUV}$ with $2048 \times 512$ pixels for the UV channel and Princeton Instruments, model Spec-10: $100 \mathrm{~B}$ with $1340 \times 100$ for the visible channel). A pc unit controls the acquisition and stores all the measured spectral data. The data acquisition is fully automated using a software developed at BIRA-IASB. A full description of the instrument can be found in Clémer et al. (2010). The configuration of the instrument permits measurement of scattered sunlight from ZS and off-axis viewing angles, as well as to perform
DS observations. Each complete MAX-DOAS scan takes approximately $20 \mathrm{~min}$ and comprises 10 different elevation angles, including ZS observations.

\section{Tropospheric $\mathrm{NO}_{2}$ vertical column retrieval algorithm}

The developed methodology for tropospheric $\mathrm{NO}_{2}$ vertical column retrieval from GB ZS-DOAS observations of scattered sunlight is based on a four-step approach. An overview of the approach is given here, while the different steps are described in detail in the following subsections. First, the ZS spectra are analysed by the DOAS spectral fitting (see Sect. 3.1). The direct output of the DOAS analysis is the differential slant column density (DSCD), which is the concentration of the trace gas of interest integrated along the effective light path with respect to a fixed amount of the same absorber in a measured reference spectrum. As many light paths contribute in the case of scattered sunlight observations, the measured slant column is a weighted average over all contributions. Air mass factors are calculated in order to model radiative transfer in the atmosphere and to convert slant columns to vertical columns (see Sect. 3.2). Ideally, the concentration of the absorber in the background spectrum should be zero. However, usually it contains low absorption from the measured species itself and therefore the residual amount in the reference spectrum (RSCD) needs to be determined accurately in order to realise the conversion from the DSCD to the total measured slant column density (MSCD) (see Sect. 3.3):

$\mathrm{MSCD}=\mathrm{DSCD}+\mathrm{RSCD}$

In the next step, the stratospheric slant column density (SSCD) is determined and removed from the total slant column in order to derive the tropospheric slant column density (TSCD) (see Sect. 3.4):

$\mathrm{TSCD}=\mathrm{MSCD}-\mathrm{SSCD}$

In the final step, TSCDs are converted to tropospheric vertical column densities (TVCDs) by using appropriate tropospheric air mass factors (TAMFs) (see Sect. 3.5):

$\mathrm{TVCD}=\frac{\mathrm{TSCD}}{\mathrm{TAMF}}$

\subsection{DOAS analysis of zenith radiance spectra}

The ZS observations of scattered sunlight are analysed by the QDOAS spectral fitting tool, developed at BIRA-IASB (Danckaert et al., 2014). The 425-490 nm visible wavelength region is used, as $\mathrm{NO}_{2}$ is characterised by strongly structured absorption lines in this fitting window, enhancing the sensitivity to the absorber, while on the other hand interference with the spectral signature of other absorbers is minimised 
in this spectral region. In addition to the relevant trace gas cross-sections $\left(\mathrm{NO}_{2}, \mathrm{O}_{3}, \mathrm{H}_{2} \mathrm{O}, \mathrm{O}_{4}\right)$, also a synthetic Ring spectrum and a low-order polynomial term are included into the non-linear least-squares fitting. They account for, respectively, the Ring effect (Grainger and Ring, 1962), i.e. the filling-in of Fraunhofer lines, and the contribution of broadband absorption and scattering effects (mainly Rayleigh and Mie scattering).

The main DOAS settings used in this study as well as the cross-sections included in the spectral fit are given in Table 1. They have been chosen in accordance with the recommendations made by the NDACC UV-Vis Working Group for the sake of harmonising the different data sets provided to the NDACC database (Van Roozendael and Hendrick, 2012).

DSCDs are the direct output of the QDOAS spectral fitting approach. Prior to further analysis, the $\mathrm{NO}_{2}$ DSCDs are quality-checked based on the following: (1) their uncertainty, expressed as standard deviation (SD), and (2) the residual structure of the retrieval fit, expressed as root mean square error (RMS). Both measures of dispersion, which can be interpreted as quality flags for the measurements, are calculated for each DSCD by the QDOAS software. An empirically derived threshold based on the $95 \%$ confidence interval is set for both parameters to determine whether or not a measurement is an outlier, e.g. due to low signal-to-noise ratio (SNR), and needs to be rejected. On a total of 4226 DSCDs retrieved based on ZS-DOAS observations, 128 were rejected after the quality check.

Beside $\mathrm{NO}_{2}$ DSCDs, also the oxygen dimer $\left(\mathrm{O}_{4}\right)$ DSCDs have been retrieved. They are essential to determine the presence of aerosols and clouds, which can both affect the tropospheric $\mathrm{NO}_{2}$ retrieval. $\mathrm{O}_{4}$ has a well-known and nearly constant column and vertical distribution in the atmosphere, mainly depending on temperature and pressure, and thus on the altitude. This makes the oxygen dimer highly sensitive to the variation of scattering due to aerosols and clouds, and therefore useful to derive information on these parameters, as discussed in Wagner et al. (2004) and Frieß et al. (2006). A high aerosol loading and/or tropospheric clouds can introduce additional multiple scattering, which can significantly enhance the light path, and subsequently the measured $\mathrm{NO}_{2}$ optical depth. This results in an overestimation of the "true" $\mathrm{NO}_{2}$ amount. The retrieved $\mathrm{NO}_{2}$ differential slant columns are screened for this effect according to the following approach: the $\mathrm{O}_{4}$ diurnal variation is first modelled with the atmospheric radiative transfer model (RTM) UVspec/DISORT (Mayer and Kylling, 2005) and the AFGL standard atmosphere, and then compared with the retrieved $\mathrm{O}_{4}$ slant columns. The nearly constant concentration of $\mathrm{O}_{4}$ in the atmosphere results in a diurnal variation characterised by a slow increase at higher SZAs, and therefore by a smooth u-shaped curve in the case of a clear and non-polluted day. An empirically derived threshold is set to determine significant offsets from the modelled $\mathrm{O}_{4}$, indicating a high aerosol loading and/or the presence of clouds introducing multiple
Table 1. Main DOAS analysis parameter settings for $\mathrm{NO}_{2}$ slant column spectral fit, in accordance with the NDACC UV-Vis Working Group recommendations (Van Roozendael and Hendrick, 2012).

\begin{tabular}{ll}
\hline Parameter & Settings \\
\hline $\begin{array}{l}\text { Fitting interval } \\
\text { Wavelength calibration method }\end{array}$ & $\begin{array}{l}425-490 \mathrm{~nm} \\
\text { Calibration based on reference } \\
\text { solar atlas Chance and } \\
\text { Kurucz (2010) }\end{array}$ \\
$\mathrm{Cross}^{\text {sections }}$ & Vandaele et al. (1998), 298 K \\
$\mathrm{NO}_{2}$ & Bogumil et al. (2003), 223 K \\
$\mathrm{O}_{3}$ & Harder and Brault (1997) \\
$\mathrm{H}_{2} \mathrm{O}$ & Hermans et al. (2003) \\
$\mathrm{O}_{4}$ & Chance and Spurr (1997) \\
$\mathrm{Ring}$ effect correction method & Polynomial of order 5 \\
Polynomial term & Slope \\
Intensity offset correction & \\
\hline
\end{tabular}

scattering. When this threshold is exceeded, the corresponding $\mathrm{NO}_{2}$ DSCD spike is identified and rejected. Without the application of the aforementioned filter strategy, a number of outliers could be observed when comparing the retrieved tropospheric $\mathrm{NO}_{2} \mathrm{VCD}$ time series with reference data. For example for day 187 (6 July 2009), such an $\mathrm{NO}_{2}$ enhancement event could be observed, as shown in Fig. 1.

\subsection{Air mass factors}

Multiple unknown light paths of scattered sunlight contribute simultaneously to the measured ZS signal. To quantify an effective light path and thus to be able to interpret the observations, radiative transfer in the atmosphere needs to be modelled. Generally the optical path is not expressed in absolute units, e.g. metres, but in terms of an air mass factor (AMF) (Solomon et al., 1987), being the ratio of the number of molecules per $\mathrm{cm}^{2}$ detected in an observation (SCD) and the integrated amount of molecules per $\mathrm{cm}^{2}$ expected for a single, vertical transect of the atmosphere (VCD):

$\mathrm{AMF}=\frac{\mathrm{SCD}}{\mathrm{VCD}}$.

AMFs are typically determined by using a radiative transfer model (RTM). It simulates the radiative transfer of electromagnetic radiation through this atmosphere, based on a priori information on the state of the atmosphere (pressure, temperature, absorbers vertical profiles, aerosol loading, cloud cover, and surface albedo). The AMF enhancement factor calculation depends also on the geometry of observation and the position of the sun.

The retrieval approach requires the calculation of stratospheric and tropospheric AMFs (see Sects. 3.4 and 3.5). Equation (4) can be reformulated for the stratosphere and troposphere as follows:

$\mathrm{SAMF}=\frac{\mathrm{SSCD}}{\mathrm{SVCD}}$ 

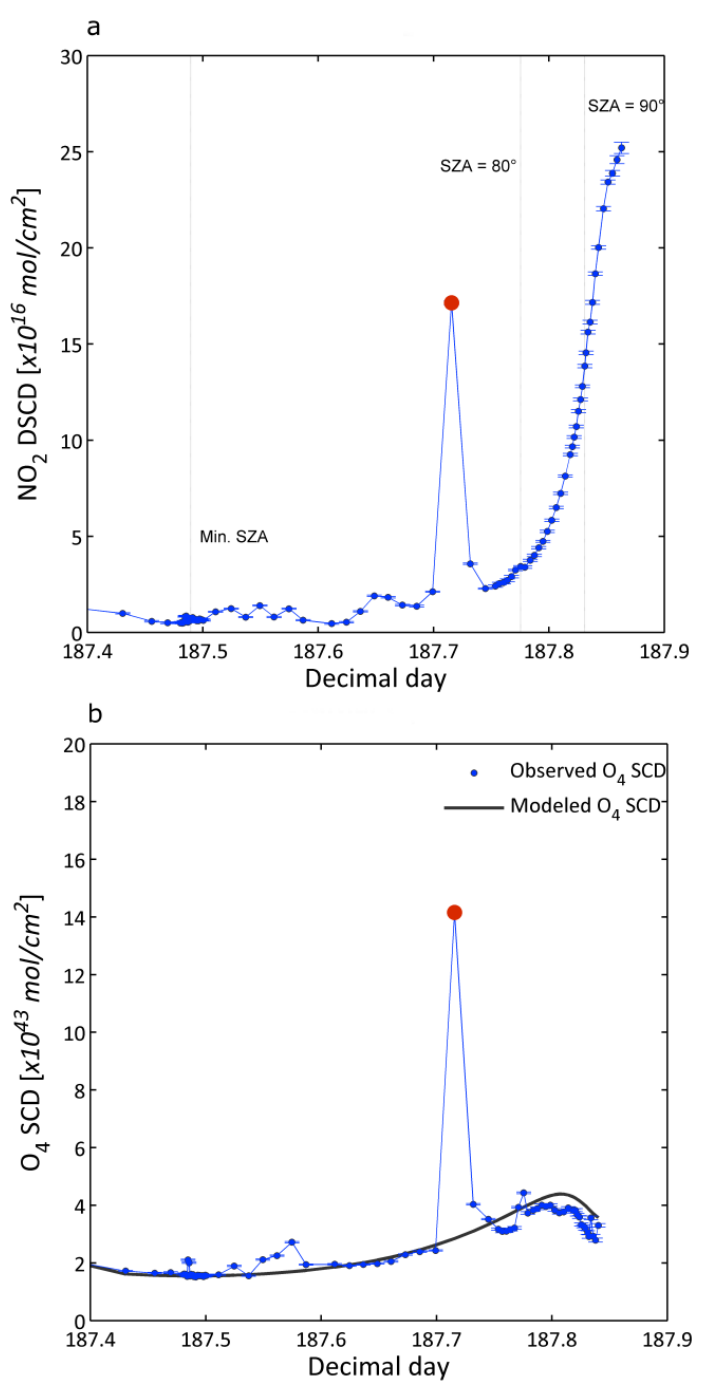

Figure 1. Example of a $\mathrm{NO}_{2}$ enhancement event, due to multiple scattering, on day 187 (6 July 2009). Both (a) the $\mathrm{NO}_{2}$ DSCD and (b) the $\mathrm{O}_{4} \mathrm{SCD}$ diurnal cycles show a large spike at approximately 17:10 LT (red dot).

and

$\mathrm{TAMF}=\frac{\mathrm{TSCD}}{\mathrm{TVCD}}$

\subsubsection{Stratospheric AMF}

Stratospheric AMFs have been calculated with the RTM package UVspec/DISORT (Mayer and Killing, 2005). This code has been thoroughly validated in the framework of an intercomparison exercise between different RTMs for the interpretation of GB ZS-DOAS and MAX-DOAS observations (Hendrick et al., 2006; Wagner et al., 2007). The radiative transfer equation (RTE) is numerically solved by the discrete ordinate method in a pseudo-spherical geometry and including multiple scattering. The wavelength used here is $457 \mathrm{~nm}$, i.e. the middle of the $\mathrm{NO}_{2}$ fitting window. Since stratospheric $\mathrm{NO}_{2}$ is characterised by a strong diurnal variation due to photochemistry, the corresponding changes of the concentration along a given light path complicate the calculation of AMFs, especially at twilight. To account for this effect, the RTM is initialised with $\mathrm{NO}_{2}$ fields depending on SZA and altitude and generated by a photochemical model. In this study, the stacked box photochemical model PSCBOX (Errera and Fonteyn, 2001; see also Hendrick et al., 2004) is coupled to the RTM UVspec/DISORT. PSCBOX includes 48 variable species, 104 gas-phase and 27 photolysis reactions and is initialised daily with 12:00 UT pressure, temperature, and chemical species profiles from the threedimensional chemical transport model (3-D CTM) SLIMCAT (Chipperfield, 2006) for the dates and location of interest. Pressure and temperature fields used in SLIMCAT are taken from UKMO (UK Meteorological Office) meteorological analyses. The output time step is $6 \mathrm{~min}$. For the calculation of stratospheric AMFs, UVspec/DISORT parameters for aerosol loading, cloud cover, and surface albedo are respectively set at summer background conditions with a visibility of $20 \mathrm{~km}$, clear-sky, and 0.07 . Then, AMFs are interpolated from the calculated $\mathrm{NO}_{2}$ AMF look-up tables to the date and time/SZA corresponding to the observations.

\subsubsection{Tropospheric AMF}

In contrast to the stratospheric contribution, tropospheric $\mathrm{NO}_{2}$ concentrations can be highly variable in time and space in polluted regions. For an optimal simulation of tropospheric AMFs, realistic a priori profiles that take into account local pollution events are required. Therefore daily $\mathrm{NO}_{2}$ and aerosol profiles retrieved from the BIRA-IASB MAX-DOAS observations performed during CINDI have been used to derive appropriate tropospheric $\mathrm{NO}_{2}$ AMFs. These calculations were done with the bePRO package based on the LIDORT RTM (Spurr et al., 2008). This RT suite, dedicated to the retrieval of trace gas and aerosol vertical profiles, and AMF calculation, based on the Optimal Estimation Method (Rodgers, 2000), is extensively described in Clémer et al. (2010) and Hendrick et al. (2014). It should be noted that in this study, polarization is not taken into account by means of a full vector RTM, such as e.g. VLIDORT (Spurr, 2006). The main reason is that past studies (see e.g. Clémer et al., 2010; Boersma et al., 2011; Lin et al., 2014) have demonstrated that the light path length (and therefore the AMF, since for AMF only light path length matters) in an optically thin atmosphere is weakly affected by polarization, in contrast to total intensities which are more affected by these effects. For instance, Clémer et al. (2010) showed that neglecting polarization can give rise to a systematic error of up to $15 \%$ for the intensities while the impact on the slant columns is significantly less $(5 \%)$. 
Tropospheric $\mathrm{NO}_{2}$ AMF look-up tables have been generated for morning and afternoon conditions based on the averaging of the daily AMFs calculated for the CINDI campaign period. For the aerosol and $\mathrm{NO}_{2}$ vertical profile retrievals, the following settings have been used: altitude grid with 10 layers of $200 \mathrm{~m}$ thickness between 0 and $2 \mathrm{~km}$, two layers of $500 \mathrm{~m}$ between 2 and $3 \mathrm{~km}$, and 1 layer between 3 and $4 \mathrm{~km}$, pressure and temperature profiles from US Standard Atmosphere, and a surface albedo of 0.07 , which is the yearly mean value extracted at $440 \mathrm{~nm}$ for Cabauw from the Koelemeijer et al. (2003) albedo climatology. Regarding the a priori profiles, an exponentially decreasing profile corresponding to an aerosol optical depth (AOD) of 0.05 and a scaling height of $1 \mathrm{~km}$ has been chosen for the aerosol retrieval. Aerosol single scattering albedo and phase moments were derived as in Clémer et al. (2010) based on co-located AERONET sun photometer measurements. In the case of $\mathrm{NO}_{2}$, a profile decreasing linearly from $0.3 \mathrm{ppb}$ at $0 \mathrm{~km}$ to $0.01 \mathrm{ppb}$ at $4 \mathrm{~km}$ was used as a priori. The a priori covariance matrices for aerosol and $\mathrm{NO}_{2}$ were constructed as in Clémer et al. (2010). It should be also noted that the stratospheric $\mathrm{NO}_{2}$ content is removed from the measured DSCDs by taking the zenith measurement of each scan as reference.

\subsection{Determination of the residual amount in the reference spectrum}

In the DOAS analysis, the concentration of $\mathrm{NO}_{2}$ is determined with respect to a fixed amount of the absorber in a selected reference spectrum. This method is commonly applied to remove the most prominent structures in the measured spectra, the so-called solar Fraunhofer lines, as they blur out the much weaker absorption structures of trace gases. Furthermore, taking the ratio of measured spectra and a Fraunhofer reference spectrum cancels out instrumental effects under the assumption that the characteristics of the instrument remain stable over a sufficiently long period. Usually this background spectrum contains (low) absorption from the measured species itself. This residual amount is, however, unknown and needs to be quantified in order to be able to determine the total measured slant column (see Eq. 1).

It should be mentioned that the concentration of the absorber in the background spectrum would be zero if an observation outside of the Earth's atmosphere could be used. This would avoid the necessity to quantify RSCD. However, as discussed in Herman et al. (2009) accurate matching of an extraterrestrial spectrum, measured with a spaceborne instrument, to the GB ZS measured spectra has proven to be hard due to the differences between the wavelength-dependent instrument slit functions. Usually an appropriate observation from the GB instrument itself serves as reference. To minimise the $\mathrm{NO}_{2}$ amount in the background spectrum, the reference is commonly taken on a non-polluted, clear-sky day around local noon, when the sun is high and therefore the atmospheric absorption, especially in the stratosphere, is low.
For the analysis of the data set, a ZS noon spectrum was selected on 21 June 2009 at 12:16 local time $\left(\mathrm{SZA}=29.3^{\circ}\right)$.

To constrain and quantify the residual amount of $\mathrm{NO}_{2}$ in the reference spectrum, the statistical minimum-amount Langley-extrapolation (MLE) method is applied, as described in Herman et al. (2009). The MLE method is based on the assumption that the minimum VCDs are constant or in other words independent from the AMF during a portion of the measurement time. The RSCD can be quantified by plotting the observed DSCDs for the whole data set in function of the associated AMFs, calculated in Sect. 3.2.1. Based on Eqs. (1) and (4) the relation between these quantities can be formulated as follows:

$\mathrm{DSCD}=\mathrm{VCD} \times \mathrm{AMF}-\mathrm{RSCD}$.

The MLE plot of the observed DSCDs and associated AMFs is given in Fig. 2. To reduce the impact of uncertainties in the calculation of the AMFs, only observations with an AMF below 5 are taken into account in the analysis. This threshold corresponds to an SZA of approximately $80^{\circ}$. The plotted DSCDs are binned in sets of 30 points per group, starting from the lowest to the highest AMF. Then in each bin, the lowest value is identified and selected. Thereafter, a linear regression is applied on the selected minima. According to Eq. (7), the additive inverse of the y-intercept gives an approximation for the residual amount in the reference spectrum. In the present case, a value of $6.2 \times 10^{15}$ molec cm $\mathrm{cm}^{-2}$ was determined based on the MLE method. It should be noted that in Chen et al. (2009), the RSCD was determined using a completely different strategy, due to the absence of days without pollution. It was based on measurements, performed when the ZS instrument was located in a clean area as close as possible to the polluted site of interest (Shanghai), in combination to co-located long-path DOAS observations.

In principle a single reference spectrum can be used for the analysis of long-term measurements if the instrumental properties stay stable. In case of instrumental instability or configuration changes, a drift or/and a bias could be found in the observations, requiring the determination of additional RSCDs for the periods corresponding to the different instrumental conditions. Instrumental stability can be monitored based on the uncertainty on the $\mathrm{NO}_{2}$ DSCDs and the RMS on the retrieval fit, both a direct product of the DOAS analysis.

Despite the limitations to quantify the $\mathrm{NO}_{2} \mathrm{RSCD}$, it should be mentioned that since a single reference is used for the analysis of the whole data set, potential errors in the RSCD determination will affect all measurements in the same way. Thus, these RSCD errors scarcely affect the relative variation of the retrieved tropospheric VCDs. 


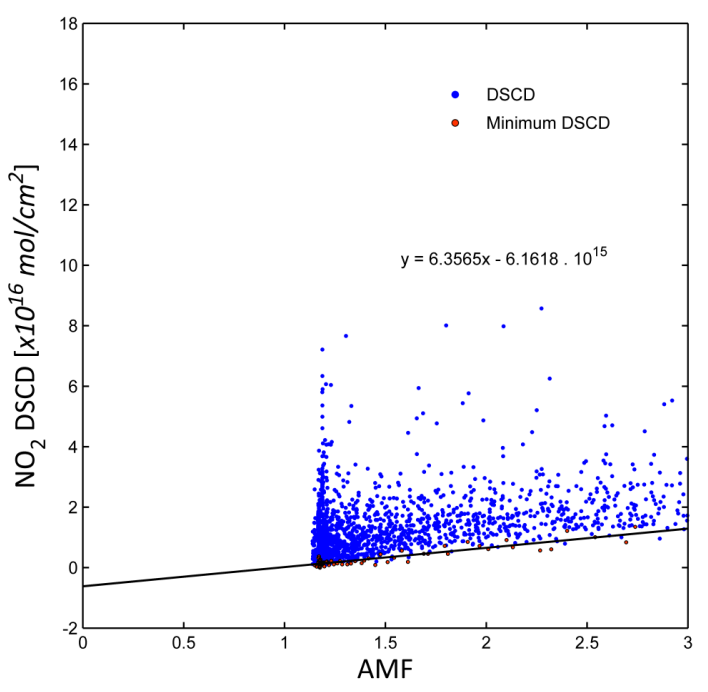

Figure 2. A value of $6.2 \times 10^{15}$ molec $\mathrm{cm}^{-2}$ is determined for the residual amount in the reference spectrum (RSCD) based on application of the MLE method. The ZS noon spectrum was selected on 21 June 2009 at 12:16 LT.

\subsection{Determination of stratospheric contribution to the total $\mathrm{NO}_{2}$ column}

In order to obtain tropospheric SCDs, stratospheric SCDs (SSCDs) need to be removed from the total measured SCDs (see Eq. 2). SSCDs are derived as follows. First, stratospheric VCDs (SVCDs) are retrieved both for $90^{\circ}$ SZA sunrise and sunset. Then output from the photochemical boxmodel PSCBOX is used to extrapolate both the $90^{\circ} \mathrm{SZA}$ twilight SVCDs to daytime values. Finally the calculated SVCDs are converted to SSCDs based on the corresponding stratospheric AMFs.

\subsubsection{Retrieval of stratospheric VCDs at sunrise and sunset}

For the retrieval of stratospheric VCDs from ZS observations at twilight, the approach recommended by the NDACC UV-Vis Working Group is followed (Van Roozendael and Hendrick, 2012). It is based on the assumption that in the case of ZS observations at dawn and dusk, the effective light path in the stratosphere is significantly longer than in the troposphere. Therefore, the tropospheric content generally does not contribute significantly to the total measured slant column (MSCD). Neglecting the $\mathrm{NO}_{2}$ tropospheric content, Eq. (5) can be rewritten as follows:

$\mathrm{SVCD}=\frac{\mathrm{MSCD}}{\mathrm{SAMF}}$

Only the twilight observations in a limited SZA range (86$91^{\circ}$ ) around $90^{\circ} \mathrm{SZA}$ are taken into account. For both sunrise and sunset, the SVCD is determined by applying a linear regression on the measurements in the above SZA range and by taking the values corresponding to $90^{\circ}$ SZA. According to Van Roozendael et al. (1994), the precision and accuracy of the SVCD retrievals are maximised at approximately $90^{\circ}$ SZA.

Despite the assumed insignificant sensitivity of twilight observations to the troposphere, tropospheric $\mathrm{NO}_{2}$ pollution events could still be observed in the measurements for a significant number of days at a place like Cabauw. The strong interference of tropospheric $\mathrm{NO}_{2}$ pollution hampers the correct retrieval of the stratospheric contribution to the total $\mathrm{NO}_{2}$ column. More precisely, it induces an overestimation of the stratospheric content. To cope with this problem, an approach is proposed to identify a non-polluted reference day and to assume that the retrieved stratospheric content for this day is representative for the whole data set, instead of a daily observation of the stratospheric $\mathrm{NO}_{2}$ amount. Various criteria need to be taken into account to evaluate and identify such a suitable reference day:

1. Identification of days with, in general, a low tropospheric $\mathrm{NO}_{2}$ contribution in the absence of local perturbations caused by tropospheric pollution events. Nonpolluted days can be differentiated based on a screening of plots of the $\mathrm{NO}_{2}$ DSCDs or SCDs as a function of SZA. The diurnal cycle of a "clean" day, dominated by stratospheric absorption, is well-defined and typically has the shape of a smooth $\mathrm{u}$-shape without perturbations (see Fig. 3.a).

2. Identification of non-overcast days with low aerosol loading based on plots of the $\mathrm{O}_{4}$ DSCDs or SCDs. The oxygen dimer is highly sensitive to variation in the aerosol concentration or in the presence of clouds as already discussed in Sect. 3.1. Days with a low aerosol loading typically have a minimal deviation from the modelled $\mathrm{O}_{4}$ diurnal variation, characterized by a smooth u-shape (see Fig. 3.b).

3. Notwithstanding the fact that the DSCDs are already quality-checked in Sect. 3.1, based on the slant error and the RMS on the fit, a reference day should be characterised by low values for both parameters.

4. Preferably a reference day should be selected near to the middle of the data set in order to minimise the bias, due to the stratospheric $\mathrm{NO}_{2}$ temporal variance and/or seasonality, between the stratospheric $\mathrm{NO}_{2}$ content of the reference day and the "true" stratospheric $\mathrm{NO}_{2}$ content of the other days.

Day 174 (23 June 2009) was selected as the best reference candidate. The corresponding SVCD values are $4.0 \times 10^{15}$ and $5.8 \times 10^{15} \mathrm{molec} \mathrm{cm}^{-2}$ for sunrise and sunset, respectively (see Fig. 4). Although this day does not meet the fourth criterion, no better candidates could be identified due to high tropospheric contamination, high aerosol loading or clouds. 

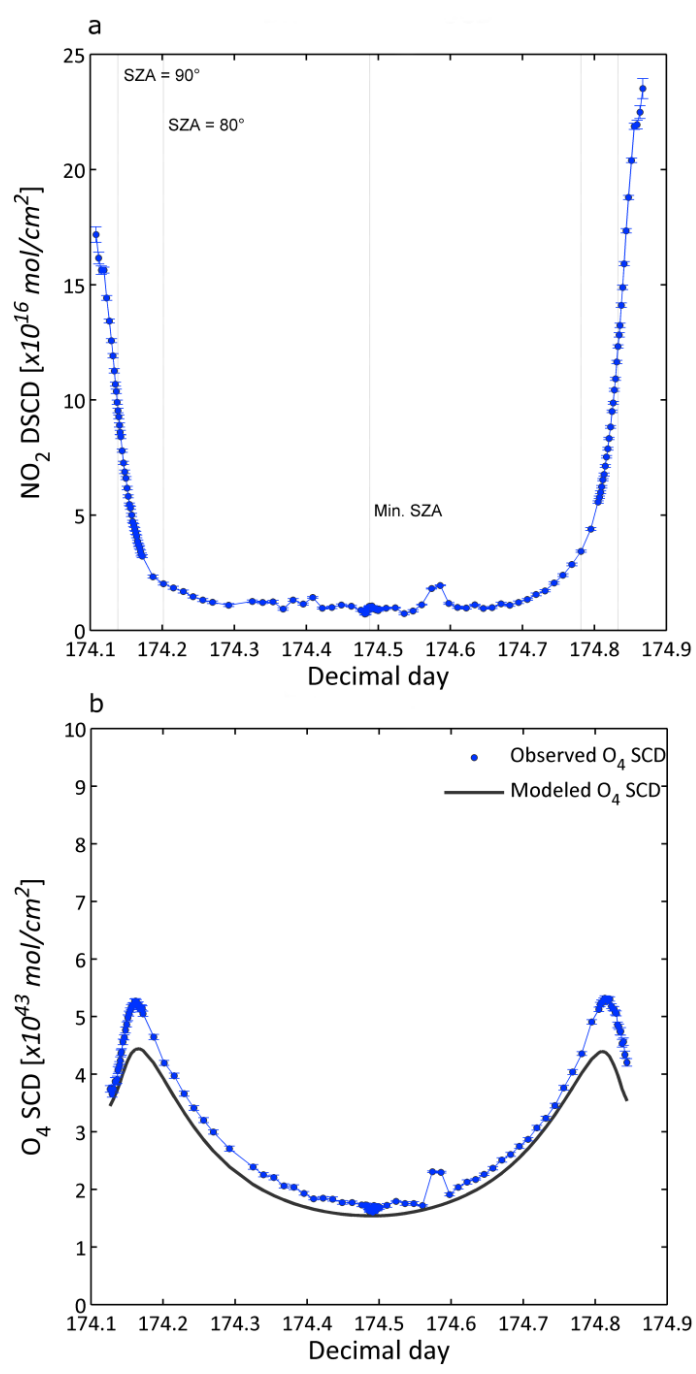

Figure 3. $\mathrm{NO}_{2}$ and $\mathrm{O}_{4}$ slant column diurnal cycle for the nonpolluted, clear-sky reference day 174 (23 June 2009). (a) $\mathrm{The}_{2}$ DSCD diurnal cycle, dominated by stratospheric absorption, has a typical u-shape with minimal tropospheric perturbations. (b) The observed $\mathrm{O}_{4} \mathrm{SCD}$ diurnal cycle largely follows the smooth curve, modelled with the RTM UVspec/DISORT.

Note that the aforementioned selection criteria are solely based on the observed spectra itself. According to correlative meteorological observations and in situ measurements (Piters et al., 2012), day 174 was also identified as a clean, non-overcast day.

Although the temporal variance of the stratospheric $\mathrm{NO}_{2}$ content can be assumed to be small over a short time interval, it is characterised by a relatively strong seasonality. Therefore, the above approach can be applied for short-term data sets like the CINDI campaign. In the case of long-term observations, especially at mid- and high-latitudes, reference days for stratospheric $\mathrm{NO}_{2}$ correction should be preferably selected at least every month, or better, on a weekly basis.

\subsubsection{Stratospheric $\mathrm{NO}_{2}$ diurnal variation modelling between sunrise and sunset}

Stratospheric $\mathrm{NO}_{2}$ is characterised by a strong diurnal cycle which depends not only on the scattering geometry but predominantly on the photochemistry, as discussed already in Sect. 3.2.1. During nighttime, $\mathrm{O}_{3}$ oxidises $\mathrm{NO}$ to $\mathrm{NO}_{2}$ in the absence of sunlight. At sunrise there is a strong decrease of $\mathrm{NO}_{2}$ due to photolysis. During daytime at mid-latitude, $\mathrm{NO}_{2}$ displays a near-linear increase due to the slow photolysis of $\mathrm{N}_{2} \mathrm{O}_{5}$. At sunset a rapid increase of $\mathrm{NO}_{2}$ occurs due to the progressive absence of photolytic loss.

In this study, the photochemical model PSCBOX described in Sect. 3.2.1 is used to calculate the rapid variation of the $\mathrm{NO}_{2}$ concentration at twilight. PSCBOX is initialised with output of the 3-D CTM SLIMCAT based on the date of the selected clean reference day. Then, the simulated $\mathrm{NO}_{2}$ diurnal cycle is made consistent with the observations and fitted on the stratospheric VCDs retrieved at twilight for the reference day: a scaling factor is calculated by taking the ratio of the retrieved and simulated stratospheric VCD at $90^{\circ}$ SZA for both sunrise and sunset and it is then interpolated for the SZA range in between. Finally, the full $\mathrm{NO}_{2}$ diurnal variation is warped on the retrieved stratospheric twilight VCDs by multiplying the simulated $\mathrm{NO}_{2}$ diurnal cycle by the varying scaling factor. Obtaining the stratospheric $\mathrm{NO}_{2}$ diurnal cycle by combining measurements and a CTM has the advantage that the model accounts for dynamical features in stratospheric $\mathrm{NO}_{2}$ while the retrieval does not depend quantitatively on the CTM. Instead it is driven by and in good agreement with the observations. The simulated and measurement-adjusted $\mathrm{NO}_{2}$ VCD diurnal cycles are both illustrated in Fig. 4.

In Chen et al. (2009), an assumption is made that the typical $\mathrm{NO}_{2}$ diurnal cycle is characterized by a quasi-linear increase and that this can be modelled by a linear interpolation between the retrieved stratospheric $\mathrm{NO}_{2} \mathrm{VCDs}$ at $90^{\circ}$ SZA sunrise and sunset. As illustrated in Fig. 4 by the red dotted curve, this assumption is valid between approximately $80^{\circ}$ SZA sunrise and sunset. Applying a linear interpolation between $90^{\circ} \mathrm{SZA}$ sunrise and sunset leads to an overestimation of the stratospheric content by approximately $1.0 \times 10^{15} \mathrm{molec}^{-2}$ with respect to the simulated diurnal variation, adjusted with measurements at $90^{\circ} \mathrm{SZA}$ sunrise and sunset. This point is further discussed in Sect. 3.6.

\subsection{Determination of the $\mathrm{NO}_{2}$ tropospheric vertical column}

Once the daytime SVCDs have been converted into SSCDs using Eq. (5), the retrieval of tropospheric $\mathrm{NO}_{2} \mathrm{VCDs}$ is straightforward (see Eqs. 2 and 3): SSCDs are removed from MSCDs and resulting TSCDs are converted into TVCDs using appropriate AMFs from the generated look-up tables (TAMFs; see Sect. 3.2.2). TVCDs are retrieved for each day 


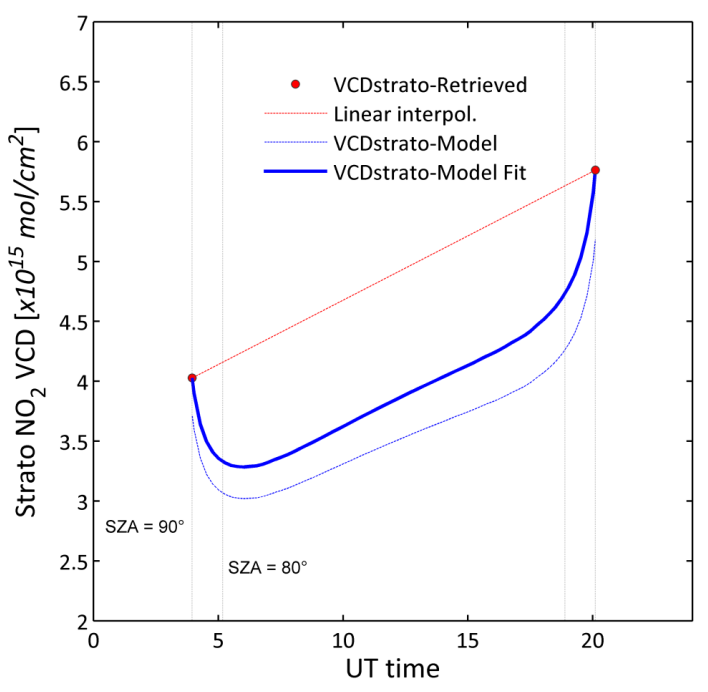

Figure 4. Representation of the retrieved stratospheric $\mathrm{NO}_{2} \mathrm{VCDs}$ at $90^{\circ} \mathrm{SZA}$ sunrise and sunset for reference day 174 (Sect. 3.4.1) and fit of the $\mathrm{NO}_{2}$ diurnal cycle modelled with the photochemical model PSCBOX.

of the data set between sunrise and sunset with usually a time interval of approximately $20 \mathrm{~min}$. For a number of days the frequency is significantly lower because of instrumental issues or the removal of observations with a large uncertainty, as it was described in Sect. 3.1. As sensitivity to the troposphere is decreasing rapidly with larger SZAs, tropospheric columns are derived only during daytime for SZAs below $80^{\circ}$.

Despite the fact that this study focuses on retrieval of tropospheric VCDs, the retrieved daytime SVCDs are also a valuable product of the approach. It should be mentioned, however, that the observed spectra are analysed with a $\mathrm{NO}_{2}$ cross-section at room temperature $(298 \mathrm{~K})$ instead of with a cross-section at $220 \mathrm{~K}$, commonly used for retrieval of stratospheric columns. Therefore, the retrieved SVCD product will be systematically overestimated, as described in Vandaele et al. (1998), due to the temperature dependency of the $\mathrm{NO}_{2}$ cross-section and the fact that the effective stratospheric $\mathrm{NO}_{2}$ temperature is not taken into account. A compensation factor is applied in order to correct the retrieved SVCDs. This factor, given by the slope of the regression between the "warm" and "cold" cross-sections, is of about 0.8 for the $220-298 \mathrm{~K}$ temperature interval.

\subsection{Error budget analysis}

To assess the tropospheric $\mathrm{NO}_{2} \mathrm{VCD}$ retrieval approach, the main error sources related to the different steps are estimated and discussed here. Based on Eqs. (1) and (2), Eq. (3) can be reformulated as follows:

$\mathrm{TVCD}=\frac{\mathrm{DSCD}+\mathrm{RSCD}-\mathrm{SSCD}}{\mathrm{TAMF}}$.
The different contributing uncertainties are assumed to be sufficiently uncorrelated with each other as they arise from nearly independent steps. The combined or overall error of the different identifiable uncertainty sources of the tropospheric $\mathrm{NO}_{2} \mathrm{VCD}$ retrieval approach can then be calculated by using the following error propagation method:

$$
\begin{aligned}
\sigma_{\mathrm{TVCD}}^{2} & =\left(\frac{\sigma_{\mathrm{DSCD}}}{\mathrm{TAMF}}\right)^{2}+\left(\frac{\sigma_{\mathrm{RSCD}}}{\mathrm{TAMF}}\right)^{2}+\left(\frac{\sigma_{\mathrm{SSCD}}}{\mathrm{TAMF}}\right)^{2} \\
& +\left(\frac{\mathrm{TSCD}}{\mathrm{TAMF}^{2}} \times \sigma_{\mathrm{TAMF}}\right)^{2} .
\end{aligned}
$$

Four main error sources are contributing to the overall uncertainty on the retrieved $\mathrm{NO}_{2}$ TVCDs: (1) random errors caused by noise in the spectral measurements and the DOAS spectral fitting $\left(\sigma_{\mathrm{DSCD}}\right),(2)$ errors originating from the estimation of the $\mathrm{NO}_{2} \mathrm{SCD}$ residual amount in the reference spectrum $\left(\sigma_{\mathrm{RSCD}}\right)$, (3) errors related to the estimation of the stratospheric contribution to the total $\mathrm{NO}_{2}$ column $\left(\sigma_{\mathrm{SSCD}}\right)$, and (4) errors in the calculation of the tropospheric AMFs $\left(\sigma_{\text {TAMF }}\right)$ caused by the uncertainties due to the assumptions made for the $\mathrm{NO}_{2}$ profile shape, aerosol effects and surface albedo.

The statistical error on the DOAS fit (1-sigma standard deviation), a direct output of the DOAS analysis, represents error source (1). Representative absolute values for $\sigma_{\mathrm{DSCD}}$ at minimum SZA around noon and high SZA at $80^{\circ}$, are typically in the order of $3.4 \times 10^{14}$ and $5.5 \times 10^{14}$ molec cm $\mathrm{cm}^{-2}$, respectively. As described in Sect. 3.1, the retrieved $\mathrm{NO}_{2}$ DSCDs are quality-checked for outliers and those are filtered out, prior to further processing.

Error source (2) is the uncertainty related to the statistical minimum-amount Langley-extrapolation method utilised for the determination of the residual amount in the reference spectrum. The RMS error on the fit is estimated to be $1.3 \times 10^{15}$ molec cm $^{-2}$

As described in Sect. 3.4, different steps are involved in the determination of the stratospheric abundance, all contributing to the overall SSCD error (error source 3 ). The corresponding error sources can be summed in quadrature to obtain an estimate for $\sigma_{\mathrm{SSCD}}$ and are the following:

i. A first main error source originates from the retrieval approach of stratospheric VCDs at $90^{\circ} \mathrm{SZA}$ at sunrise and sunset. As the air mass, which is sampled at twilight, might be several hundred kilometres further away towards the sun, the effective SZA at the location of the air mass is lower than the $90^{\circ} \mathrm{SZA}$ at the measurement station, used so far in the standard NDACC retrieval. To take this effect into account, stratospheric VCDs have been also retrieved at $87^{\circ} \mathrm{SZA}$ at sunrise and sunset and the impact on the tropospheric VCDs has been investigated. The retrieved stratospheric VCDs corresponding to $87^{\circ} \mathrm{SZA}$ are approximately $3.7 \times 10^{14} \mathrm{molec}^{-2}$ lower than at $90^{\circ} \mathrm{SZA}$. This causes an average increase of the retrieved tropospheric VCDs of $5 \%$. 
ii. $\mathrm{NO}_{2}$ diurnal cycle by the stacked box photochemical model and the assimilation with the retrieved stratospheric VCDs at sunrise and sunset. Previous sensitivity studies taking into account uncertainties related to $\mathrm{NO}_{x}$ partitioning reaction rates, $\mathrm{O}_{3}$ and temperature profiles, and aerosol loading pointed out that $20 \%$ is a conservative value for the uncertainty on modelled stratospheric $\mathrm{NO}_{2}$ VCDs and profiles (Preston et al., 1997; Bracher et al., 2005).

iii. The third main error source is the uncertainty on the stratospheric AMFs, which is mainly due to the choice of the RT model settings. Several studies (e.g. Solomon et al., 1987; Van Roozendael et al., 1994; Ionov et al., 2008) showed that this uncertainty is of about $10 \%$ at $90^{\circ}$ SZA.

iv. The fourth error source, contributing to the overall SSCD error, results from the selection of a fixed reference day to determine the stratospheric content and the assumption of temporal invariance of stratospheric $\mathrm{NO}_{2}$. Although the variation of the stratospheric $\mathrm{NO}_{2}$ content is small at mid-latitude in summer over a short time interval, like the duration of the CINDI campaign, this error is taken into account by estimating the maximal variation between the simulations of the $\mathrm{NO}_{2}$ diurnal cycle for all days of the acquisition period. This uncertainty is found to be approximately of $1.8 \mathrm{x}$ $10^{14}$ molec cm $^{-2}$.

Errors in the calculation of the tropospheric AMFs, due to uncertainties in the RT model parameters, are the major error source (4). They affect the retrievals in a systematic way. In Chen et al. (2009) and Wang et al. (2012), a thorough sensitivity study is applied with varying input parameters in the radiative transfer simulations. The influence of parameters such as aerosol and $\mathrm{NO}_{2}$ layer height, $\mathrm{AOD}$ and $\mathrm{NO}_{2}$ profile, surface albedo, etc. has been tested. Based on these sensitivity studies, the uncertainty on TAMF is estimated to range between 10 and $20 \%$ for SZAs between 20 and $85^{\circ}$. As in our retrieval approach, daily $\mathrm{NO}_{2}$ and aerosol profiles, retrieved from the MAX-DOAS observations, were utilised instead of model data for the a priori profile shape, it is assumed that $\sigma_{\text {TAMF }}$ should be definitely within the estimated uncertainties. This is confirmed by the estimation of the uncertainty on the AMFs due to the variability of the $\mathrm{NO}_{2}$ vertical profiles retrieved during CINDI, which is found to be of $12 \%$ on average.

Results of the error budget analysis are summarised in Table 2 and are visualised in Fig. 5. In Table 2, the typical relative errors are presented according to the observed tropospheric $\mathrm{NO}_{2}$ amount: (1) low (below 33th percentile or $<0.6 \times 10^{16}$ molec $\mathrm{cm}^{-2}$ ), (2) moderate (between 33th and 66th percentile or 0.6 and $1.0 \times 10^{16} \mathrm{molec} \mathrm{cm}^{-2}$ ), and (3) high (above 66th percentile or $>1.0 \times 10^{16} \mathrm{molec} \mathrm{cm}^{-2}$ ) $\mathrm{NO}_{2}$ TVCD values. For each $\mathrm{NO}_{2}$ TVCD range, the mean
Table 2. Error budget on the retrieved tropospheric $\mathrm{NO}_{2}$ VCDs. The typical relative and absolute errors (in percent and $10^{15}$ molec $\mathrm{cm}^{-2}$ respectively) are given for low (below 33th percentile or $<0.6 \times 10^{16}$ molec $\mathrm{cm}^{-2}$ ), moderate (between 33th and 66th percentile or 0.6 and $1.0 \times 10^{16}$ molec $\mathrm{cm}^{-2}$ ) and high (above 66 th percentile or $>1.0 \times 10^{16}$ molec $\mathrm{cm}^{-2}$ ) $\mathrm{NO}_{2}$ TVCD values, respectively. The last column gives the typical uncertainties on all retrieved TVCDs.

\begin{tabular}{lrrrr}
\hline $\begin{array}{l}\text { Error } \\
\text { source }\end{array}$ & Low TVCD & Mod TVCD & High TVCD & Total TVCD \\
\hline$\sigma_{\mathrm{DSCD}}$ & $14 \%(0.5)$ & $6 \%(0.4)$ & $3 \%(0.5)$ & $8 \%(0.5)$ \\
$\sigma_{\mathrm{RSCD}}$ & $40 \%(1.3)$ & $16 \%(1.3)$ & $9 \%(1.3)$ & $22 \%(1.3)$ \\
$\sigma_{\mathrm{SSCD}}$ & $20 \%(0.8)$ & $19 \%(1.5)$ & $19 \%(3.1)$ & $19 \%(1.8)$ \\
$\sigma_{\mathrm{TAMF}}$ & $13 \%(0.2)$ & $14 \%(0.2)$ & $15 \%(0.2)$ & $14 \%(0.2)$ \\
\hline$\sigma_{\mathrm{TVCD}}$ & $38 \%(1.3)$ & $24 \%(1.9)$ & $21 \%(3.5)$ & $28 \%(2.2)$ \\
\hline
\end{tabular}

relative uncertainty $\sigma$ is given for both the individual main error sources and the corresponding overall errors.

The error budget indicates that the overall uncertainty $\sigma_{\mathrm{TVCD}}$ on the retrieved $\mathrm{NO}_{2}$ TVCDs is on average of $28 \%$. Larger errors $(\sim 40 \%)$ are obtained in case of small TVCD values. In this case, the errors are dominated by uncertainties in the determination of the $\mathrm{NO}_{2} \mathrm{SCD}$ residual amount in the reference spectrum. For moderate and high TVCD values, the corresponding overall relative errors are of $24 \%$ and $21 \%$ respectively. In these conditions, the main error sources are the determination of the stratospheric $\mathrm{NO}_{2}$ abundance and the calculation of tropospheric AMFs. Errors related to the DOAS retrieval $\left(\sigma_{\mathrm{DSCD}}\right)$ and to the determination of the residual amount $\left(\sigma_{\mathrm{RSCD}}\right)$ seem to drop in case of larger $\mathrm{NO}_{2}$ TVCDs, while errors originating from the determination of the stratospheric $\mathrm{NO}_{2}$ abundance $\left(\sigma_{\mathrm{SSCD}}\right)$ do not depend significantly on the TVCD values. Errors due to the calculation of tropospheric AMFs $\left(\sigma_{\mathrm{TAMF}}\right)$, on the other hand, slightly increase with increasing TVCDs. In Fig. 5 the estimated overall absolute and relative errors are plotted in function of the retrieved $\mathrm{NO}_{2}$ TVCDs. It can be seen that the largest absolute errors are associated with the largest TVCD values as expected. The relative errors, on the other hand, which can be up to $100 \%$ in case of very low tropospheric contributions show a steep and rapid drop in case of increasing TVCDs. The relative error is almost constant $(\sim 22 \%)$ for $\mathrm{NO}_{2}$ TVCDs larger than $2.0 \times 10^{16}$ molec $\mathrm{cm}^{-2}$.

\section{Retrieval results - correlative comparison}

The tropospheric $\mathrm{NO}_{2}$ columns have been compared with correlative data sets in order to thoroughly assess our ZS retrieval algorithm. To ensure comparability of data, and to reduce instrumental and algorithmic differences, a set of measurement requirements were defined in the framework of CINDI, which had to be performed by all instruments to the greatest possible extent (Piters et al., 2012). The same 


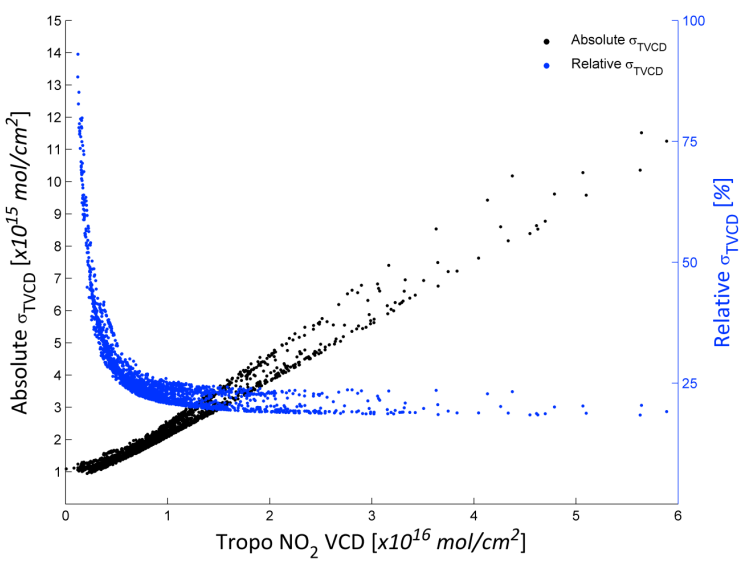

Figure 5. Overall absolute and relative errors $\left(\sigma_{\mathrm{TVCD}}\right)$ on the retrieved $\mathrm{NO}_{2}$ TVCDs.

holds for the parameter settings for the trace gas retrieval as well as the relevant cross-sections included in the spectral fit (Roscoe et al., 2010). A first comparison is done with the VCDs obtained from a SAOZ instrument, which has been operated during the CINDI campaign in the close proximity of the BIRA-IASB instrument. Then the retrieval results are compared with VCDs from MAX-DOAS and DS-DOAS observations, also performed with the BIRA-IASB instrument.

\subsection{ZS-DOAS SAOZ}

The ZS-DOAS SAOZ instrument was developed by CNRSLATMOS at the end of the 1980s. Since then, about 20 SAOZ instruments have been installed at various latitudes on the globe, with initially the measurement of stratospheric ozone and $\mathrm{NO}_{2}$ as main objective. Instrumental set-up was described in Pommereau and Goutail (1998) and Piters et al. (2012) for the CINDI campaign. During the CINDI campaign, a measurement was done every $2 \mathrm{~min}$, resulting in a high frequency of ZS observations. The retrieval strategy is discussed in Dieudonné et al. (2013).

\subsection{MAX-DOAS}

In addition to zenith-sky observations, the BIRA-IASB MAX-DOAS instrument measured scattered sunlight at different elevation angles towards the horizon, hereby increasing the sensitivity to absorbers present close to the ground. The azimuth was fixed along a west-north-westerly direction $\left(287^{\circ}\right)$ with an unobstructed view down to an elevation angle of $0.5^{\circ}$. Tropospheric $\mathrm{NO}_{2}$ vertical profiles and corresponding VCDs have been retrieved by applying the bePRO profiling tool (Clémer et al., 2010; Hendrick et al., 2014) to the measured off-axis DSCDs. Retrieval settings are described in Sect. 3.2.2.

\subsection{DS-DOAS}

The BIRA-IASB instrument is also able to perform observations of direct solar irradiance. $\mathrm{NO}_{2}$ vertical columns can be accurately retrieved based on the DS-DOAS approach as the light path through the atmosphere, and subsequently the AMF, is straightforward to model. The determination of the AMF does not require complex radiative transfer calculations, but can be geometrically derived as the secant of the SZA. This significantly reduces uncertainties in the conversion from slant to vertical columns. The stratospheric contribution, determined as described in Sect. 3.4, is subtracted from the total $\mathrm{NO}_{2}$ columns in order to obtain tropospheric VCDs. A major drawback of the DS observation is the dependency on clear-sky conditions. As cloud cover was substantial during the CINDI campaign, the acquired DS-DOAS data set is relatively scarce. The fundamentals of DS-DOAS are extensively discussed in Brewer et al. (1973), Cede et al. (2006), and Herman et al. (2009).

\subsection{Discussion of the correlative comparison}

The comparisons between ZS-DOAS and SAOZ, ZS-DOAS and MAX-DOAS, and ZS-DOAS and DS-DOAS are shown in Fig. 6. A complete scan with the BIRA-IASB instrument, consisting of 10 off-axis measurements at different elevation angles including zenith takes approximately $20 \mathrm{~min}$ of measurement time. The frequency of ZS measurements is therefore much lower than in the case of the SAOZ, which is an instrument dedicated to perform only ZS observations (approximately one measurement every $2 \mathrm{~min}$ ). To reduce the effect of temporal variability in the tropospheric signals in combination with different measurement sampling, and in order to intercompare the different data sets in a meaningful way, the retrievals are averaged in $30 \mathrm{~min}$ bins. An overall good agreement can be observed between ZS-DOAS, SAOZ, MAX-DOAS and DS-DOAS during the CINDI campaign, demonstrating the robustness and reliability of the presented approach.

Figure 7 shows the scatter plot and linear regression analysis of the binned and averaged $\mathrm{NO}_{2}$ TVCDs, retrieved for the whole time series from (a) ZS-DOAS vs. SAOZ, and (b) ZS-DOAS vs. MAX-DOAS, respectively. For both comparisons, a correlation coefficient higher than 0.9 can be observed. The linear regression analysis shows slopes within $18 \%$ of unity and intercepts close to zero. In case of small $\mathrm{NO}_{2}$ TVCD retrievals, we see a positive bias for the SAOZ with respect to ZS-DOAS retrievals, while the bias gets negative at higher TVCD values. The tropospheric $\mathrm{NO}_{2}$ retrieval algorithms applied are different in concept, so their error budget is different and they also feature different sensitivities to the vertical distribution of $\mathrm{NO}_{2}$. In this study the overall uncertainty on retrieved tropospheric vertical column densities (TVCDs) has been estimated to $28 \%$ on average for TVCDs $>5 \times 10^{15} \mathrm{molec}^{-2}$ and of the order 

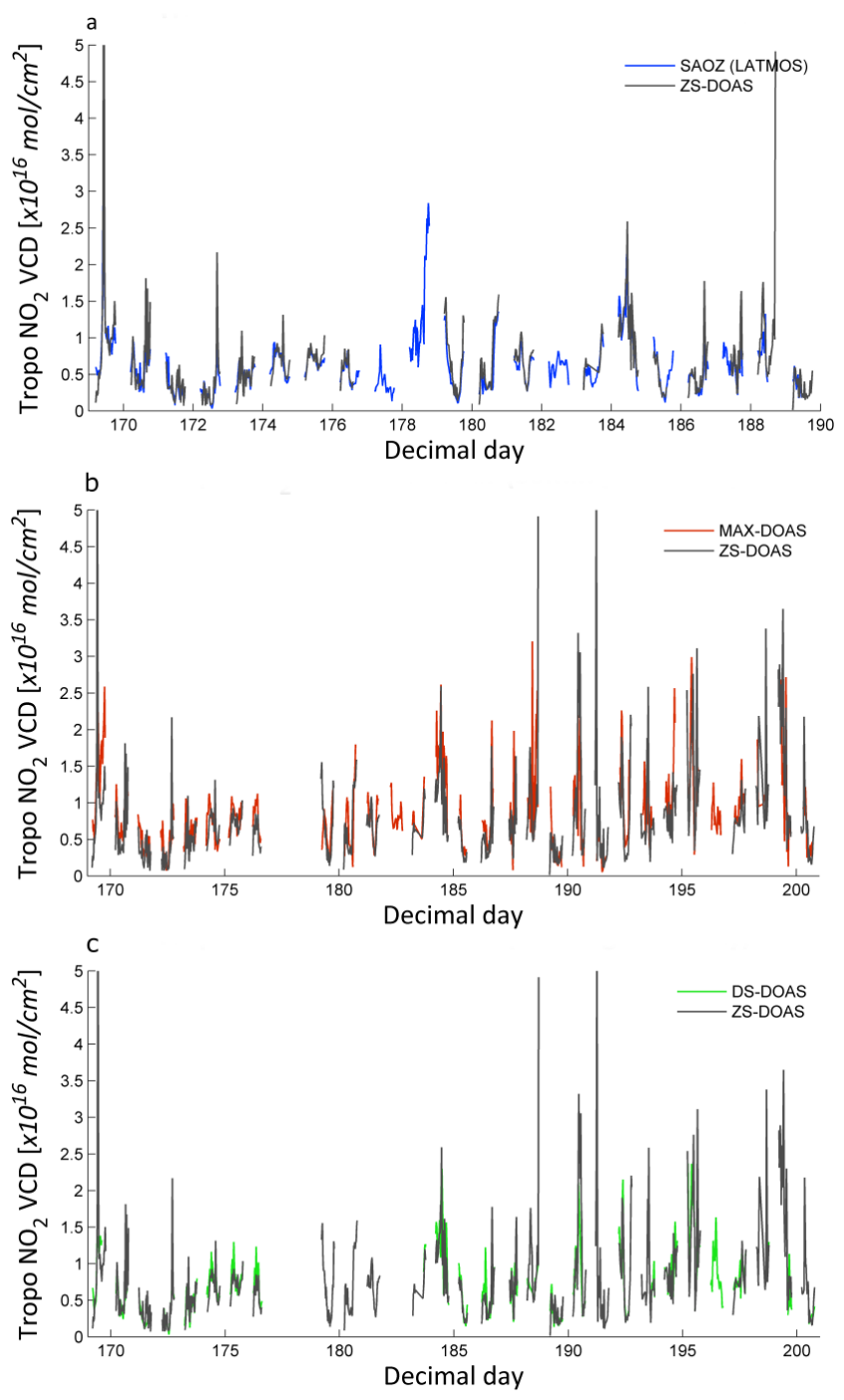

Figure 6. Comparisons of the tropospheric $\mathrm{NO}_{2}$ VCD time series, between (a) ZS-DOAS and SAOZ, (b) ZS-DOAS and MAXDOAS, and (c) ZS-DOAS and DS-DOAS. TVCDs are binned and averaged in time slots of $30 \mathrm{~min}$.

of $1 \times 10^{15}$ molec $\mathrm{cm}^{-2}$ for smaller TVCDs. On the other hand, the uncertainty on MAX-DOAS $\mathrm{NO}_{2}$ retrievals has been estimated in a recent study by Hendrick et al. (2014) to be comprised between 12 and $30 \%$, a significant part of this error being systematic in nature. Therefore the scatter can be explained to a large extent by combined uncertainties on the different retrieval algorithms. According to Roscoe et al. (2010), a part of the scatter can also be attributed to the combination of the temporal variability in the tropospheric signals and different measurement sampling, as averaging the retrievals in 30 min bins reduces, but does not eliminate this effect.

In Figure 8 the $\mathrm{NO}_{2}$ TVCD daily mean time series, retrieved from (a) ZS-DOAS and SAOZ, and (b) ZS-DOAS and MAX-DOAS, respectively, are compared. A very good con- sistency can be observed between the ZS-DOAS and SAOZ $\mathrm{NO}_{2}$ TVCD retrievals, for both low and high TVCD values. The MAX-DOAS retrievals show similar day-to-day variations with respect to the ZS-DOAS and SAOZ retrievals. However, a positive bias of about $18 \%$ on average can be observed for MAX-DOAS retrievals.

The same feature can be seen in Fig. 9, showing the retrieved $\mathrm{NO}_{2}$ TVCD diurnal cycle of 2 subsequent days in the data set, i.e. 3 July 2009 (day 184; see Fig. 9a) and 4 July 2009 (day 185; see Fig. 9b). For most retrievals, MAX-DOAS data shows a positive offset while ZS-DOAS and SAOZ retrievals are very close to each other. Different air masses were sampled in both cases due to the different viewing geometries of the multi-axis and zenith-sky approach. This can lead to increased uncertainties especially if the horizontal distribution of $\mathrm{NO}_{2}$ is inhomogeneous and in the presence of scattered clouds, as to be expected in a site like Cabauw. It should also be noted that MAX-DOAS has a higher sensitivity to $\mathrm{NO}_{2}$ present close to the ground than the other techniques. In Fig. 9, also the DS-DOAS retrievals are plotted. To avoid smoothing due to interpolation between the limited number of retrievals and for a better interpretation of the results, DS-DOAS retrievals are represented as point data. The DS-DOAS retrievals are seen to be in good agreement with the TVCDs retrieved by the other approaches.

It is clear from the observations that day-to-day tropospheric $\mathrm{NO}_{2}$ concentrations can have a high variability at the Cabauw site. For day 184 (3 July), many tropospheric $\mathrm{NO}_{2}$ pollution events can be observed. On the other hand, day 185 (4 July) is a clean day with low tropospheric $\mathrm{NO}_{2}$ values, showing a smooth decrease in the morning and a slow buildup starting from noon. The meteorological parameters have shown that the $\mathrm{NO}_{2}$ concentration variability is strongly depending on wind direction. On day 184 , there were moderate winds $\left(4.3 \mathrm{~m} \mathrm{~s}^{-1}\right)$ from the southwest. The regions north of Cabauw are relatively clean, while there are strong pollution sources in the west (Rotterdam) and the south (industrial Flanders). When the wind is blowing from the south or west, retrievals from the Ozone Monitoring Instrument (OMI) as well as CHIMERE simulations over Cabauw have shown tropospheric $\mathrm{NO}_{2}$ columns that are approximately 2 times higher than on days with winds from the north or east (Piters et al., 2012). On day 185 there was a light breeze $\left(2.5 \mathrm{~m} \mathrm{~s}^{-1}\right)$ from the northwest. On this day, the air over Cabauw was dominated by cleaner air originating from the North Sea.

\section{Discussion and recommendations}

In this section, the presented retrieval approach is briefly discussed with a focus on recommendations to improve the applicability on ZS observations acquired at other GB stations. From the error budget analysis, it can be concluded that reliable $\mathrm{NO}_{2}$ TVCDs can be retrieved in case of moderate and strong polluted sites. Cabauw is a typical example of such a 

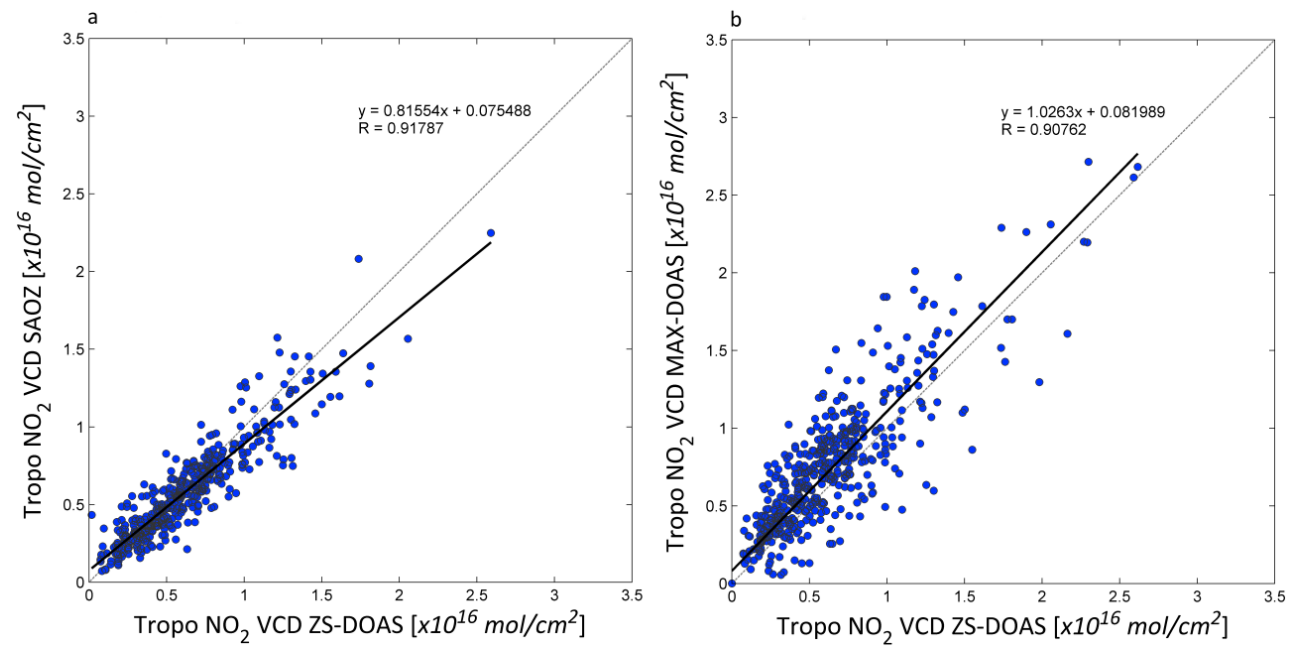

Figure 7. Scatter plot and linear regression analysis of the TVCDs retrieved for the whole time series from (a) ZS-DOAS and SAOZ, and (b) ZS-DOAS and MAX-DOAS, respectively. TVCDs are binned and averaged in $30 \mathrm{~min}$ bins.
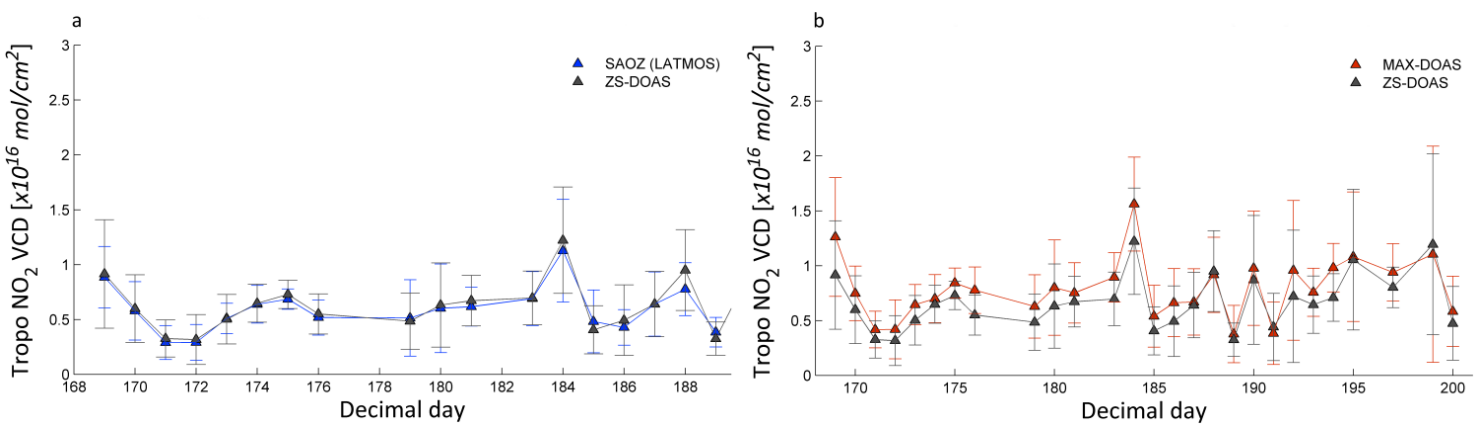

Figure 8. TVCD daily mean time series for (a) ZS-DOAS and SAOZ, and (b) ZS-DOAS and MAX-DOAS, respectively.

site as it is a semi-rural area, in the direct proximity of the four largest cities of the Netherlands. Depending on the meteorological conditions, the city may therefore be subject to substantial pollution events. In case of application of the retrieval approach on ZS observations performed at a station with very low or very high tropospheric content, some recommendations are made below.

Application of chemically modified Langley plots (Lee et al., 1994), which are frequently used for determination of the $\mathrm{NO}_{2}$ residual amount in the reference spectrum, was meaningless in the case of the Cabauw data set. Only the observations in a limited SZA range $\left(90-80^{\circ}\right)$ with low tropospheric sensitivity could be used, since tropospheric pollution events can affect the straight-line fits of the Langley plot method. Along with the low frequency of ZS observations, i.e. each 15 to $20 \mathrm{~min}$, too few data points remained in the plot to be statistically relevant. Furthermore, some tropospheric contamination could still be observed, even at high SZA. Constantin et al. (2013) reported similar issues with the chemically modified Langley plot method, when applied on observations from a polluted site. For the selection of the SZA interval, a trade-off was discussed between having a sufficiently large set of observations while avoiding tropospheric contamination at lower SZA. In case of low to moderate tropospheric content, it is however strongly recommended to apply both the MLE and the chemically modified Langley plot methods in order to further constrain the determination of the residual amount in the reference spectrum and to reduce the substantial uncertainties in this step.

Another important error source is the determination of the stratospheric contribution. The assumption that the tropospheric contribution is negligible in the case of ZS observations at dawn and dusk does not always count in case of sites where frequent strong pollution events occur. Therefore, an approach was proposed to identify a non-polluted reference day and to assume that the retrieved stratospheric content for this day is representative for the whole data set. It is recommended, however, to use daily observations (or to take a weekly mean) of the stratospheric $\mathrm{NO}_{2}$ amount in the absence of frequent tropospheric pollution events in order to reduce the uncertainties introduced by the temporal variance and/or seasonality of the stratospheric $\mathrm{NO}_{2}$ content. 

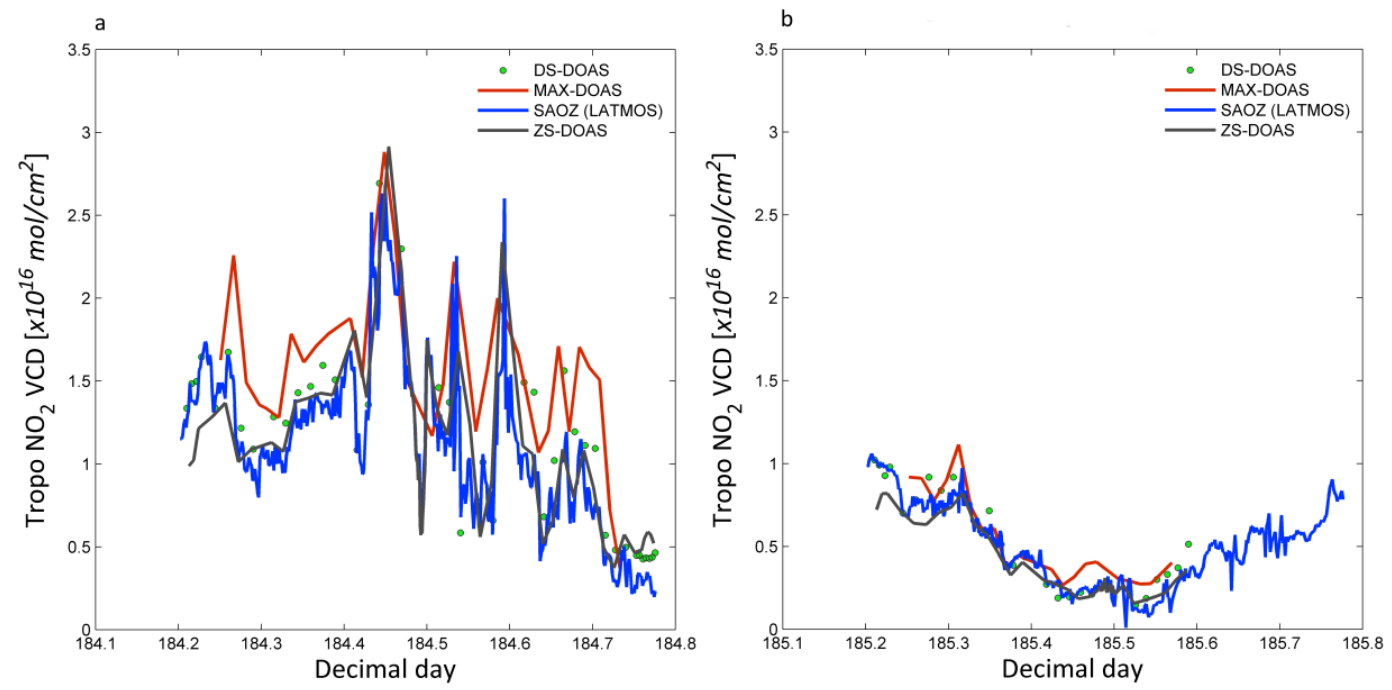

Figure 9. TVCD diurnal variation for (a) a day with many pollution events (day 184) and (b) a non-polluted day (185), respectively. To avoid smoothing due to interpolation between the limited number of retrievals and for a better interpretation of the results, DS-DOAS retrievals are represented as point data here.

In Chen et al. (2009) a strategy was applied to determine the stratospheric contribution in case of a heavy polluted site. Due to severe tropospheric contamination at the measurement site in Shanghai (China), no clean reference day could be identified in the data set. Instead, measurements were done at Chongming Island, which lies to the northeast of Shanghai in the Pacific Ocean. Chongming can be considered as the area with the smallest tropospheric $\mathrm{NO}_{2}$ pollution in the proximity of Shanghai. The SVCDs determined for a clean day at Chongming Island were eventually used to retrieve the TVCDs from the observations acquired in Shanghai. This strategy can be, however, an additional error source, because of the spatial and temporal variations of the stratospheric $\mathrm{NO}_{2}$ content. It makes also difficult its application to any other station due to the need of these additional measurements in a clean site.

\section{Application at the NDACC site OHP}

The potential of the presented ZS retrieval algorithm is also demonstrated by its application on observations acquired at the NDACC station Observatoire de Haute Provence (OHP, $43.94^{\circ} \mathrm{N}, 5.71^{\circ} \mathrm{E}, \sim 650 \mathrm{~m}$ a.s.l.), where BIRA-IASB and LATMOS operate a MAX-DOAS (UV channel only) and a SAOZ instrument, respectively. OHP is a mostly remote site at mid-latitude in Southern France, affected from time to time by pollution events coming from the Marseille area (South of OHP). Tropospheric columns are retrieved for a 2-year period from August 2012 to July 2014.

Taken the recommendations of Sect. 5 into account, slightly different strategies are applied in the different steps of the retrieval approach. (1) For the determination of the
RSCD, the comparison between the chemically modified Langley plot and the MLE method shows consistent results when applied on observations acquired at a background station like OHP. Both a higher frequency of ZS observations and the lack of frequent tropospheric contamination results in a sufficiently large and reliable data set to derive the RSCD by linear least-squares regression in the chemically modified Langley plot. A single noon spectrum, selected on 31 August 2013 at 11:40 LT, is used for the analysis of the whole time series. For the RSCD, a value of $2.7 \times 10^{15} \mathrm{molec} \mathrm{cm}^{-2}$ is determined. (2) Due to the absence of frequent tropospheric pollution events at twilight, daily observations of the stratospheric contribution could be performed instead of retrieving the stratospheric content for a number of reference days, representative for parts of the data set. This strategy reduces the uncertainties introduced by the temporal variance and/or seasonality of the stratospheric $\mathrm{NO}_{2}$ content. (3) A seasonally resolved climatology of tropospheric $\mathrm{NO}_{2}$ AMFs has been generated based on the lower tropospheric $\mathrm{NO}_{2}$ vertical profiles retrieved by applying the bePRO algorithm (see Sect. 3.2.2) to the August 2012 to July 2014 MAX-DOAS measurements at OHP. At this station, the MAX-DOAS instrument operates only in the UV at the following elevation angles: $2,4,6,8,11,26$, and $90^{\circ}$ (zenith). Regarding the a priori $\mathrm{NO}_{2}$ profiles, exponentially decreasing profiles corresponding to the vertical columns determined by the geometrical approximation and a scaling height of $0.5 \mathrm{~km}$ has been chosen. In the case of aerosol retrievals, a single extinction profile taken from the LOWTRAN climatology and corresponding to background conditions has been used as a priori. The retrieval altitude grid is one layer of $150 \mathrm{~m}$ thickness between 0.65 (altitude of the station) and $0.8 \mathrm{~km}$ alti- 


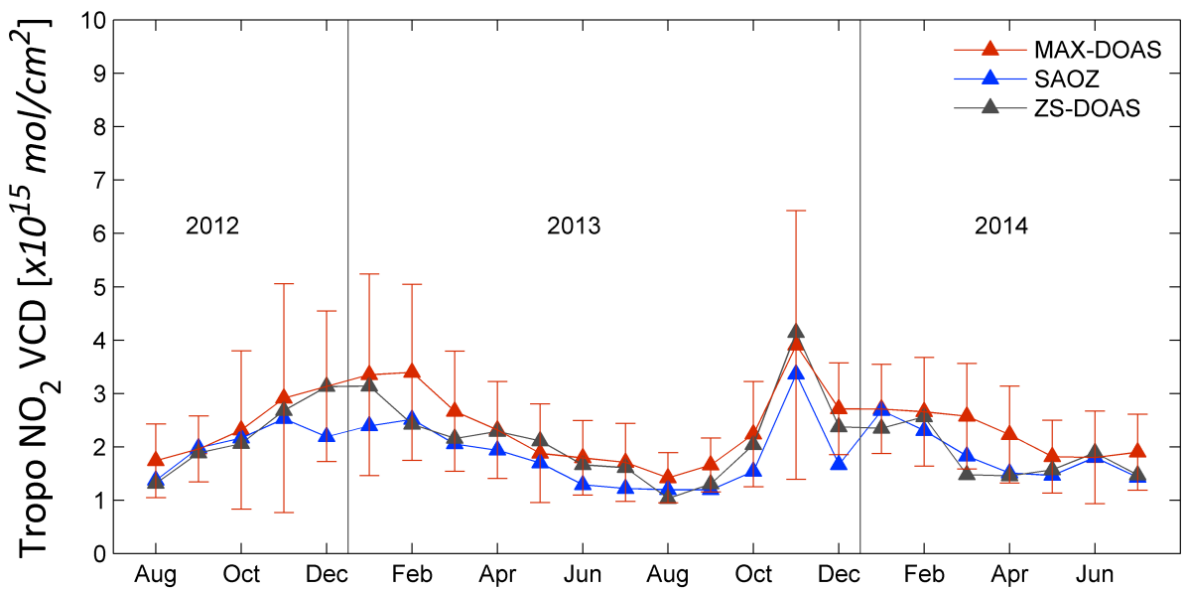

Figure 10. TVCD monthly mean time series at the OHP station for ZS-DOAS, SAOZ and MAX-DOAS for the period August 2012-July 2014. The error bars on the MAX-DOAS data points correspond to the 1-sigma standard deviation.

tude, 10 layers of $200 \mathrm{~m}$ thickness between 0.8 and $3 \mathrm{~km}$, and one layer of $1 \mathrm{~km}$ thickness between 3 and $4 \mathrm{~km} . \mathrm{NO}_{2}$ and aerosol extinction profiles have been retrieved at 370 and $360 \mathrm{~nm}$, respectively. In the case of AMF calculation, the following wavelengths were selected: 370 and $460 \mathrm{~nm}$. These two sets of UV and visible AMFs have been used for the application of the ZS approach to the MAX-DOAS and SAOZ measurements, respectively. For the calculation of AMFs in the visible, the aerosol profiles retrieved at $360 \mathrm{~nm}$ have been converted to $460 \mathrm{~nm}$ using the Ångström exponents derived from collocated CIMEL/AERONET sun photometer measurements (http://aeronet.gsfc.nasa.gov; see also Wang et al., 2014. MAX-DOAS $\mathrm{NO}_{2}$ vertical columns involved in the comparison with the ZS method have been derived by integrating the retrieved $\mathrm{NO}_{2}$ vertical profiles.

The retrieved TVCDs have been compared again with correlative data sets from SAOZ and MAX-DOAS observations and the resulting monthly mean time series are shown in Fig. 10. At OHP, a marked seasonal cycle can be observed with a maximum in winter with mean values close to $3 \times 10^{15}$ molec $\mathrm{cm}^{-2}$ and a minimum in summer with mean values around $1.7 \times 10^{15} \mathrm{molec} \mathrm{cm}^{-2}$. In general the three data sets are in good agreement for both low and high TVCDs: the correlation coefficients are respectively 0.82 and 0.88 for the comparison of ZS-DOAS with MAX-DOAS and with SAOZ. These results further support the good reliability of the ZS retrieval approach presented in this study.

\section{Summary and conclusions}

An algorithm for retrieving tropospheric $\mathrm{NO}_{2} \mathrm{VCDs}$ from GB ZS-DOAS measurements has been presented, with a full characterisation of the different retrieval steps. This algorithm has been developed and tested based on ZS observations from the BIRA-IASB MAX-DOAS instrument, ac- quired during the CINDI campaign at Cabauw, The Netherlands. For the tropospheric VCDs, a median value of $7.9 \times 10^{15}$ molec $\mathrm{cm}^{-2}$ can be observed at the Cabauw site with maxima up to $6.0 \times 10^{16}$ molec $\mathrm{cm}^{-2}$. The retrievals are in good agreement when compared to TVCDs retrieved from off-axis and DS observations, and ZS measurements acquired by a co-located SAOZ instrument. For both comparisons a correlation higher than 0.9 can be observed with slopes within $18 \%$ of unity and intercepts close to zero. The main error sources are characterised for the four principal steps of the retrieval approach:

1. Uncertainties due to the DOAS analysis and noise in the spectral measurements result in a relative error of approximately 14 and $3 \%$ for low and high tropospheric VCD retrievals, respectively. It should be noted that DSCDs are quality-checked, including the removal of outliers, and compensated for multiple scattering events prior to the retrieval.

2. The $\mathrm{NO}_{2} \mathrm{SCD}$ residual amount in the fixed reference spectrum, measured on a non-polluted, clear-sky day around local noon, is determined based on the statistical minimum-amount Langley-extrapolation method. The related uncertainty can be substantial $(22 \%$ on average and up to $40 \%$ in case of low $\mathrm{NO}_{2}$ TVCDs). However, since a single RSCD is used for the analysis of the whole data set, potential errors scarcely affect the relative variation of the retrieved tropospheric VCDs.

3. The stratospheric contribution to the total column is determined based on a two-step approach. First, stratospheric VCDs are retrieved for both $90^{\circ}$ SZA sunrise and sunset for the selected reference day (23 June 2009). Then the $\mathrm{NO}_{2}$ diurnal variation between the $90^{\circ} \mathrm{SZA}$ twilight observations, modelled by the photochemical box-model PSCBOX, is fitted to these observations. The 
overall error for this step is estimated to be around $19 \%$. It accounts for the uncertainties due to (1) the determination of the effective SZA corresponding to the twilight observations, (2) the modelling of the $\mathrm{NO}_{2}$ diurnal variation, (3) the simulation of stratospheric AMFs, and (4) the assumption of the temporal invariance of stratospheric $\mathrm{NO}_{2}$ during the CINDI campaign period.

4. In the last step of the retrieval approach, tropospheric $\mathrm{NO}_{2}$ slant columns retrieved between $80^{\circ}$ SZA sunrise and sunset are converted to vertical columns by using appropriate tropospheric AMFs. Errors on the calculation of the tropospheric AMFs are estimated to range between 10 and $20 \%$, depending on the SZA.

In general, the error budget analysis indicates that tropospheric $\mathrm{NO}_{2}$ VCDs can be retrieved with the ZS approach with an uncertainty $\sigma_{\mathrm{TVCD}}$ of less than $28 \%$. In case of low tropospheric content, the relative errors are found to be higher (i.e. in the order of $40 \%$ ) and are dominated by uncertainties in the determination of the residual amount in the reference spectrum. In case of strong tropospheric pollution events, the overall error drops to approximately $22 \%$. So the TVCD retrievals are generally more reliable in case of large tropospheric contributions, as expected, and for such conditions, the largest uncertainties find their origins in the determination of the stratospheric $\mathrm{NO}_{2}$ abundance $(19 \%)$ and the calculation of tropospheric AMFs (15\%).

The present study demonstrates that ZS observations, widely used for monitoring of the stratospheric composition for more than 3 decades, are also suitable for the retrieval of tropospheric $\mathrm{NO}_{2}$ column amounts, despite the lower sensitivity to the troposphere when compared to MAX-DOAS observations. In order to further demonstrate the potential of the presented retrieval algorithm, it has been successfully applied on a 2-year data set acquired at OHP, being a background site from time to time affected by pollution events. This offers new perspectives for the exploitation of ZS UVVis observations at NDACC stations, and the applicability of the algorithm on data from other stations as well as longer time series will be further investigated. At present, there are far more ZS-DOAS than MAX-DOAS GB stations at various latitudes and much longer time series of ZS observations are available than for MAX-DOAS, mainly due to the novelty of the latter technique. This makes the ZS retrieval approach relevant for investigating the long-term evolution of tropospheric $\mathrm{NO}_{2}$, with a feed-back of more than 2 decades at some stations.

Acknowledgements. The CINDI Campaign was largely funded by the ESA project CEOS (ESRIN 22202/09/I-EC) and the EU project ACCENT-AT2 (GOCE-CT-2004-505337). We further acknowledge the support of the European Union Seventh Framework Programme via the NORS project (FP7-284421) and the ACTRIS project (FP7-262254). BIRA-IASB is also thankful for the support from the Belgian Federal Science Policy Office through the AGACC-II project (SD/CS/07A). M. P. Chipperfield, from the University of Leeds, is gratefully acknowledged for providing us with the SLIMCAT data. The team of LATMOS wishes to thank the French Centre National d'Etudes Spatiales (CNES) and Institut des Sciences de l'Univers (INSU). The authors also want to express their gratitude to the KNMI staff at Cabauw for their technical support and the offered infrastructure.

Edited by: F. Boersma

\section{References}

Beirle, S., Kühl, S., Puk,i-te, J., and Wagner, T.: Retrieval of tropospheric column densities of $\mathrm{NO}_{2}$ from combined SCIAMACHY nadir/limb measurements, Atmos. Meas. Tech., 3, 283299, doi:10.5194/amt-3-283-2010, 2010.

Berg, N., Mellqvist, J., Jalkanen, J.-P., and Balzani, J.: Ship emissions of $\mathrm{SO}_{2}$ and $\mathrm{NO}_{2}$ : DOAS measurements from airborne platforms, Atmos. Meas. Tech., 5, 1085-1098, doi:10.5194/amt-51085-2012, 2012.

Boersma, K. F., Eskes, H. J., Dirksen, R. J., van der A, R. J., Veefkind, J. P., Stammes, P., Huijnen, V., Kleipool, Q. L., Sneep, M., Claas, J., Leitão, J., Richter, A., Zhou, Y., and Brunner, D.: An improved tropospheric $\mathrm{NO}_{2}$ column retrieval algorithm for the Ozone Monitoring Instrument, Atmos. Meas. Tech., 4, 19051928, doi:10.5194/amt-4-1905-2011, 2011.

Bogumil, K., Orphal, J., Homann, T., Voigt, S., Spietz, P., Fleischmann, O. C., Vogel, A., Hartmann, M., Bovensmann, H., Frerik, J., and Burrows, J. P.: Measurements of molecular absorption spectra with the SCIAMACHY Pre-Flight Model: Instrument characterization and reference spectra for atmospheric remote sensing in the $230-2380 \mathrm{~nm}$ region, J. Photochem. Photobiol. A, 157, 167-184, 2003.

Bracher, A., Sinnhuber, M., Rozanov, A., and Burrows, J. P.: Using a photochemical model for the validation of $\mathrm{NO}_{2}$ satellite measurements at different solar zenith angles, Atmos. Chem. Phys., 5, 393-408, doi:10.5194/acp-5-393-2005, 2005.

Brewer, A. W., McElroy, C. T., and Kerr, J. B.: Nitrogen dioxide concentrations in the atmosphere, Nature, 246, 129-133, 1973.

Bucsela, E. J., Krotkov, N. A., Celarier, E. A., Lamsal, L. N., Swartz, W. H., Bhartia, P. K., Boersma, K. F., Veefkind, J. P., Gleason, J. F., and Pickering, K. E.: A new stratospheric and tropospheric $\mathrm{NO}_{2}$ retrieval algorithm for nadir-viewing satellite instruments: applications to OMI, Atmos. Meas. Tech. Discuss., 6, 1361-1407, doi:10.5194/amtd-6-1361-2013, 2013.

Cede, A., Herman, J., Richter, A., Krotkov, N., and Burrows, J.: Measurements of nitrogen dioxide total column amounts at Goddard Space Flight Center using a Brewer spectrometer in direct sun mode, J. Geophys. Res., 111, D05304, doi:10.1029/2005JD006585, 2006.

Chan, A. W. H., Chan, M. N., Surratt, J. D., Chhabra, P. S., Loza, C. L., Crounse, J. D., Yee, L. D., Flagan, R. C., Wennberg, P. O., and Seinfeld, J. H.: Role of aldehyde chemistry and $\mathrm{NO}_{x}$ concentrations in secondary organic aerosol formation, Atmos. Chem. Phys., 10, 7169-7188, doi:10.5194/acp-10-7169-2010, 2010.

Chance, K. V. and Spurr, R. J. D.: Ring effect studies: Rayleigh scattering, including molecular parameters for rotational Raman 
scattering, and the Fraunhofer spectrum, Appl. Optics, 36, 52245230, 1997.

Chance, K. and Kurucz, R. L.: An improved high-resolution solar reference spectrum for Earth's atmosphere measurements in the ultraviolet, visible, and near infrared, available at: http://www. cfa.harvard.edu/atmosphere (last access: September 2013), 2010.

Chen, D., Zhou, B., Beirle, S., Chen, L. M., and Wagner, T.: Tropospheric $\mathrm{NO}_{2}$ column densities deduced from zenith-sky DOAS measurements in Shanghai, China, and their application to satellite validation, Atmos. Chem. Phys., 9, 3641-3662, doi:10.5194/acp-9-3641-2009, 2009.

Chipperfield, M. P.: New version of the TOMCAT/SLIMCAT offline chemical transport model: Intercomparison of stratospheric tracer experiments, Q. J. Roy. Meteor. Soc., 132, 1179-1203, doi:10.1256/qj.05.51, 2006.

Clémer, K., Van Roozendael, M., Fayt, C., Hendrick, F., Hermans, C., Pinardi, G., Spurr, R., Wang, P., and De Mazière, M.: Multiple wavelength retrieval of tropospheric aerosol optical properties from MAXDOAS measurements in Beijing, Atmos. Meas. Tech., 3, 863-878, doi:10.5194/amt-3-863-2010, 2010.

Constantin, D.-E., Merlaud, A., Van Roozendael, M., Voiculescu, M., Fayt, C., Hendrick, F., Pinardi, G., and Georgescu, L.: Measurements of tropospheric $\mathrm{NO}_{2}$ in Romania using a zenith-sky mobile DOAS system and comparisons with satellite observations, Sensors, 13, 3922-3940, doi:10.3390/s130303922, 2013.

Crutzen, P.: The influence of nitrogen oxides on the atmospheric ozone content, Q. J. Roy. Meteor. Soc., 96, 320-325, 1970.

Crutzen, P. J.: The role of $\mathrm{NO}$ and $\mathrm{NO}_{2}$ in the chemistry of the troposphere and stratosphere, Annu. Rev. Earth Planet. Sci., 7, 443-472, 1979.

Denis, L., Roscoe, H. K., Chipperfield, M. P., Van Roozendael, M., and Goutail, F.: A new software suite for $\mathrm{NO}_{2}$ vertical profile retrieval from ground-based zenith-sky spectrometers, J. Quant. Spectrosc. Ra., 92, 321-333, doi:10.1016/j.jqsrt.2004.07.030, 2005.

Dieudonné, E., Ravetta, F., Pelon, J., Goutail, F., and Pommereau, J. P.: Linking $\mathrm{NO}_{2}$ surface concentration and integrated content in the urban developed atmospheric boundary layer, Geophys. Res. Lett., 40, 1247-1251, doi:10.1002/grl.50242, 2013.

Errera, Q. and Fonteyn, D.: Four-dimensional variational chemical assimilation of CRISTA stratospheric measurements, J. Geophys. Res., 106, 12253-12265, doi:10.1029/2001JD900010, 2001.

Danckaert, T., Fayt, C., and Van Roozendael, M.: QDOAS software user manual 2.108, IASB/BIRA, Uccle, Belgium, 2014, available at: http://uv-vis.aeronomie.be/software/QDOAS/QDOAS_ manual.pdf, last access: 4 November 2014.

Frieß, U., Monks, P. S., Remedios, J. J., Rozanov, A., Sinreich, R., Wagner, T., and Platt, U.: MAX-DOAS $\mathrm{O}_{4}$ measurements: A new technique to derive information on atmospheric aerosols: 2. Modeling studies, J. Geophys. Res., 111, D14203, doi:10.1029/2005JD006618, 2006.

Goutail, F., Pommereau, J.-P., and Sarkissian, A.: Total nitrogen dioxide at the Arctic Polar Circle since 1990, Geophys. Res. Lett., 21, 1371-1374, 1994.

Grainger, J. F. and Ring, J.: Anomalous Fraunhofer line profiles, Nature, 193, p. 762, 1962.
Harder, J. W. and Brault, J. W.: Atmospheric measurements of water vapor in the 442-nm region, J. Geophys. Res., 102, 6245-6252, doi:10.1029/96JD01730, 1997.

Hendrick, F., Barret, B., Van Roozendael, M., Boesch, H., Butz, A., De Mazière, M., Goutail, F., Hermans, C., Lambert, J.C., Pfeilsticker, K., and Pommereau, J.-P.: Retrieval of nitrogen dioxide stratospheric profiles from ground-based zenithsky UV-visible observations: validation of the technique through correlative comparisons, Atmos. Chem. Phys., 4, 2091-2106, doi:10.5194/acp-4-2091-2004, 2004.

Hendrick, F., Van Roozendael, M., Kylling, A., Petritoli, A., Rozanov, A., Sanghavi, S., Schofield, R., von Friedeburg, C., Wagner, T., Wittrock, F., Fonteyn, D., and De Mazière, M.: Intercomparison exercise between different radiative transfer models used for the interpretation of ground-based zenith-sky and multi-axis DOAS observations, Atmos. Chem. Phys., 6, 93-108, doi:10.5194/acp-6-93-2006, 2006.

Hendrick, F., Müller, J.-F., Clémer, K., Wang, P., De Mazière, M., Fayt, C., Gielen, C., Hermans, C., Ma, J. Z., Pinardi, G., Stavrakou, T., Vlemmix, T., and Van Roozendael, M.: Four years of ground-based MAX-DOAS observations of HONO and NO2 in the Beijing area, Atmos. Chem. Phys., 14, 765-781, doi:10.5194/acp-14-765-2014, 2014.

Herman, J., Cede, A., Spinei, E., Mount, G., Tzortziou, M., and Abuhassan, N.: $\mathrm{NO}_{2}$ column amounts from ground-based Pandora and MFDOAS spectrometers using the direct-sun DOAS technique: Intercomparisons and application to OMI validation, J. Geophys. Res., 114, D13307, doi:10.1029/2009JD011848, 2009.

Hermans, C., Vandaele, A. C., Fally, S., Carleer, M., Colin, R., Coquart, B., Jenouvrier, A., and Mérienne, M.-F.: Absorption crosssection of the collision-induced bands of oxygen from the UV to the NIR, in: Proceedings of the NATO Advanced Research Workshop, Weakly Interacting Molecular Pairs: Unconventional Absorbers of Radiation in the Atmosphere, Fontevraud, France, 24 April-2 May 2002, edited by: Camy-Peyret, C. and Vigasin, A. A., NATO Science Series IV Earth and Environmental Sciences, vol. 27, Kluwer Academic Publishers, Boston, 193-202, 2003.

Hilboll, A., Richter, A., Rozanov, A., Hodnebrog, Ø., Heckel, A., Solberg, S., Stordal, F., and Burrows, J. P.: Improvements to the retrieval of tropospheric $\mathrm{NO}_{2}$ from satellite - stratospheric correction using SCIAMACHY limb/nadir matching and comparison to Oslo CTM2 simulations, Atmos. Meas. Tech., 6, 565-584, doi:10.5194/amt-6-565-2013, 2013.

Hönninger, G., von Friedeburg, C., and Platt, U.: Multi axis differential optical absorption spectroscopy (MAX-DOAS), Atmos. Chem. Phys., 4, 231-254, doi:10.5194/acp-4-231-2004, 2004.

Ionov, D. V., Timofeyev, Y. M., Sinyakov, V. P., Semenov, V. K., Goutail, F., Pommereau, J.-P., Bucsela, E. J., Celarier, E. A., and Kroon, M.: Ground-based validation of EOS-Aura OMI $\mathrm{NO}_{2}$ vertical column data in the midlatitude mountain ranges of Tien Shan (Kyrgyzstan) and Alps (France), J. Geophys. Res., 113, D15S08, doi:10.1029/2007JD008659, 2008.

Johansson, M., Rivera, C., de Foy, B., Lei, W., Song, J., Zhang, Y., Galle, B., and Molina, L.: Mobile mini-DOAS measurement of the outflow of $\mathrm{NO}_{2}$ and $\mathrm{HCHO}$ from Mexico City, Atmos. Chem. Phys., 9, 5647-5653, doi:10.5194/acp-9-5647-2009, 2009. 
Koelemeijer, R. B. A., de Haan, J. F., and Stammes, P.: A database of spectral surface reflectivity in the range $335-772 \mathrm{~nm}$ derived from 5.5 years of GOME observations, J. Geophys. Res., 108, 4070, doi:10.1029/2002JD002429, 2003.

Lee, A. M., Roscoe, H. K., Oldham, D. J., Squires, J. A. C., Sarkissian, A., and Pommereau, J.-P.: Improvements to the accuracy of zenith-sky measurements of $\mathrm{NO}_{2}$ by visible spectrometers, J. Quant. Spectr. Rad. Transfer, 52, 649-657, 1994.

Lin, J.-T., Martin, R. V., Boersma, K. F., Sneep, M., Stammes, P., Spurr, R., Wang, P., Van Roozendael, M., Clémer, K., and Irie, H.: Retrieving tropospheric nitrogen dioxide from the Ozone Monitoring Instrument: effects of aerosols, surface reflectance anisotropy, and vertical profile of nitrogen dioxide, Atmos. Chem. Phys., 14, 1441-1461, doi:10.5194/acp-14-1441-2014, 2014.

Mayer, B. and Kylling, A.: Technical note: The libRadtran software package for radiative transfer calculations - description and examples of use, Atmos. Chem. Phys., 5, 1855-1877, doi:10.5194/acp-5-1855-2005, 2005.

McKenzie, R., Johnston, P. V., McElroy, C. T., Kerr, J. B., and Solomon, S.: Altitude distributions of stratospheric constituents from ground-based measurements at twilight, J. Geophys. Res., 96, 15499-15511, 1991.

Merlaud, A., Van Roozendael, M., van Gent, J., Fayt, C., Maes, J., Toledo-Fuentes, X., Ronveaux, O., and De Mazière, M.: DOAS measurements of $\mathrm{NO}_{2}$ from an ultralight aircraft during the Earth Challenge expedition, Atmos. Meas. Tech., 5, 2057-2068, doi:10.5194/amt-5-2057-2012, 2012.

Noxon, J. F.: Nitrogen dioxide in the stratosphere and troposphere measured by ground-based absorption spectroscopy, Science, 189, 547-549, 1975.

Piters, A. J. M., Boersma, K. F., Kroon, M., Hains, J. C., Van Roozendael, M., Wittrock, F., Abuhassan, N., Adams, C., Akrami, M., Allaart, M. A. F., Apituley, A., Beirle, S., Bergwerff, J. B., Berkhout, A. J. C., Brunner, D., Cede, A., Chong, J., Clémer, K., Fayt, C., Frieß, U., Gast, L. F. L., Gil-Ojeda, M., Goutail, F., Graves, R., Griesfeller, A., Großmann, K., Hemerijckx, G., Hendrick, F., Henzing, B., Herman, J., Hermans, C., Hoexum, M., van der Hoff, G. R., Irie, H., Johnston, P. V., Kanaya, Y., Kim, Y. J., Klein Baltink, H., Kreher, K., de Leeuw, G., Leigh, R., Merlaud, A., Moerman, M. M., Monks, P. S., Mount, G. H., Navarro-Comas, M., Oetjen, H., Pazmino, A., Perez-Camacho, M., Peters, E., du Piesanie, A., Pinardi, G., Puentedura, O., Richter, A., Roscoe, H. K., Schönhardt, A., Schwarzenbach, B., Shaiganfar, R., Sluis, W., Spinei, E., Stolk, A. P., Strong, K., Swart, D. P. J., Takashima, H., Vlemmix, T., Vrekoussis, M., Wagner, T., Whyte, C., Wilson, K. M., Yela, M., Yilmaz, S., Zieger, P., and Zhou, Y.: The Cabauw Intercomparison campaign for Nitrogen Dioxide measuring Instruments (CINDI): design, execution, and early results, Atmos. Meas. Tech., 5, 457-485, doi:10.5194/amt-5-457-2012, 2012.

Platt, U.: Differential optical absorption spectroscopy (DOAS), in: Air Monitoring by Spectroscopic Techniques, edited by: Sigrist, M. W., 127, John Wiley \& Sons, Hoboken, N.J., USA, 27-83, 1994.

Platt, U. and Stutz, J.: Differential Optical Absorption Spectroscopy: Principles and Applications, Springer-Verlag, Berlin, Germany, 597 pp., 2008.
Pommereau, J. P. and Goutail, F.: Stratospheric $\mathrm{O}_{3}$ and $\mathrm{NO}_{2}$ Observations at the Southern Polar Circle in summer and fall 1988, Geophys. Res. Lett., 15, 895-897, doi:10.1029/GL015i008p00895, 1988.

Popp, C., Brunner, D., Damm, A., Van Roozendael, M., Fayt, C., and Buchmann, B.: High-resolution $\mathrm{NO}_{2}$ remote sensing from the Airborne Prism EXperiment (APEX) imaging spectrometer, Atmos. Meas. Tech., 5, 2211-2225, doi:10.5194/amt-5-22112012, 2012.

Preston, K. E., Jones, R. L. and Roscoe, H. K.: Retrieval of $\mathrm{NO}_{2}$ vertical profiles from ground-based UV-visible measurements: Method and validation, J. Geophys. Res., 102, 10089-10097, 1997.

Richter, A. and Burrows, J. P.: Retrieval of Tropospheric $\mathrm{NO}_{2}$ from GOME Measurements, Adv. Space Res., 29, 1673-1683, 2002.

Rodgers, C. D.: Inverse methods for atmospheric sounding: theory and practice, Ser. Atmos. Oceanic Planet. Phys., vol. 2, F.W. Taylor, World Sci., Hackensack, NY, USA, 2000.

Roscoe, H. K., Van Roozendael, M., Fayt, C., du Piesanie, A., Abuhassan, N., Adams, C., Akrami, M., Cede, A., Chong, J., Clémer, K., Friess, U., Gil Ojeda, M., Goutail, F., Graves, R., Griesfeller, A., Grossmann, K., Hemerijckx, G., Hendrick, F., Herman, J., Hermans, C., Irie, H., Johnston, P. V., Kanaya, Y., Kreher, K., Leigh, R., Merlaud, A., Mount, G. H., Navarro, M., Oetjen, H., Pazmino, A., Perez-Camacho, M., Peters, E., Pinardi, G., Puentedura, O., Richter, A., Schönhardt, A., Shaiganfar, R., Spinei, E., Strong, K., Takashima, H., Vlemmix, T., Vrekoussis, M., Wagner, T., Wittrock, F., Yela, M., Yilmaz, S., Boersma, F., Hains, J., Kroon, M., Piters, A., and Kim, Y. J.: Intercomparison of slant column measurements of $\mathrm{NO}_{2}$ and $\mathrm{O}_{4}$ by MAX-DOAS and zenith-sky UV and visible spectrometers, Atmos. Meas. Tech., 3, 1629-1646, doi:10.5194/amt-3-1629-2010, 2010.

Solomon, S., Schmeltekopf, A. L., and Sanders, R. W.: On the interpretation of zenith sky measurements, J. Geophys. Res., 92, 8311-8319, doi:10.1029/JD092iD07p08311, 1987.

Solomon, S., Portmann, R. W., Sanders, R. W., Daniel, J. S., Madsen, W., Bartram, B., and Dutton, E. G.: On the role of nitrogen dioxide in the absorption of solar radiation, J. Geophys. Res., 10, 12047-12058, doi:10.1029/1999JD900035, 1999.

Spurr, R.: Vlidort: A linearized pseudo-spherical vector discrete ordinate radiative transfer code for forward model and retrieval studies in multilayer multiple scattering media, J. Quant. Spectrosc. Ra., 102, 316-342, 2006.

Spurr, R.: Lidort and Vlidort: Linearized pseudo-spherical scalar and vector discrete ordinate radiative transfer models for use in remote sensing retrieval problems, Light Scattering Reviews, Volume 3, edited by: Kokhanovsky, A., Springer, Berlin, 229275, 2008.

Valks, P., Pinardi, G., Richter, A., Lambert, J.-C., Hao, N., Loyola, D., Van Roozendael, M., and Emmadi, S.: Operational total and tropospheric $\mathrm{NO}_{2}$ column retrieval for GOME-2, Atmos. Meas. Tech., 4, 1491-1514, doi:10.5194/amt-4-1491-2011, 2011.

Vandaele, A.-C., Hermans, C., Simon, P.C., Carleer, M., Colin, R., Fally, S., Mérienne, M.-F., Jenouvrier, A. and Coquart, B.: Measurements of the NO2 absorption cross-section from $42000 \mathrm{~cm}$ 1 to $10000 \mathrm{~cm}-1(238-1000 \mathrm{~nm})$ at $220 \mathrm{~K}$ and $294 \mathrm{~K}$, J. Quant. Spectrosc. Ra., 59, 171-184, 1998. 
Van Roozendael, M., De Mazière, M., and Simon, P. C.: Groundbased visible measurements at the Jungfraujoch station since 1990, J. Quant. Spectrosc. Ra., 52, 231-240, 1994.

Van Roozendael, M., and Hendrick, F.: Recommendations for $\mathrm{NO}_{2}$ column retrieval from NDACC zenith-sky UVVIS spectrometers, BIRA-IASB, Uccle, Belgium, available at: http://ndacc-uvvis-wg.aeronomie.be/tools/NDACC UVVIS-WG_NO2settings_v4.pdf, last access: 24 October 2014, 2012.

Vlemmix, T., Piters, A. J. M., Berkhout, A. J. C., Gast, L. F. L., Wang, P., and Levelt, P. F.: Ability of the MAX-DOAS method to derive profile information for NO2: can the boundary layer and free troposphere be separated?, Atmos. Meas. Tech., 4, 26592684, doi:10.5194/amt-4-2659-2011, 2011.

Wagner, T., Dix, B., Friedeburg, C. v., Frieß, U., Sanghavi, S., Sinreich, R., and Platt, U.: MAX-DOAS $\mathrm{O}_{4}$ measurements: A new technique to derive information on atmospheric aerosols - Principles and information content, J. Geophys. Res., 109, D22205, doi:10.1029/2004JD004904, 2004.

Wagner, T., Burrows, J. P., Deutschmann, T., Dix, B., von Friedeburg, C., Frieß, U., Hendrick, F., Heue, K.-P., Irie, H., Iwabuchi, H., Kanaya, Y., Keller, J., McLinden, C. A., Oetjen, H., Palazzi, E., Petritoli, A., Platt, U., Postylyakov, O., Pukite, J., Richter, A., van Roozendael, M., Rozanov, A., Rozanov, V., Sinreich, R., Sanghavi, S., and Wittrock, F.: Comparison of box-airmass-factors and radiances for Multiple-Axis Differential Optical Absorption Spectroscopy (MAX-DOAS) geometries calculated from different UV/visible radiative transfer models, Atmos. Chem. Phys., 7, 1809-1833, doi:10.5194/acp-7-1809-2007, 2007.
Wagner, T., Ibrahim, O., Shaiganfar, R., and Platt, U.: Mobile MAX-DOAS observations of tropospheric trace gases, Atmos. Meas. Tech., 3, 129-140, doi:10.5194/amt-3-129-2010, 2010.

Wagner, T., Beirle, S., Brauers, T., Deutschmann, T., Frieß, U., Hak, C., Halla, J. D., Heue, K. P., Junkermann, W., Li, X., Platt, U., and Pundt-Gruber, I.: Inversion of tropospheric profiles of aerosol extinction and $\mathrm{HCHO}$ and $\mathrm{NO}_{2}$ mixing ratios from MAX-DOAS observations in Milano during the summer of 2003 and comparison with independent data sets, Atmos. Meas. Tech., 4, 2685-2715, doi:10.5194/amt-4-2685-2011, 2011.

Wang, S., Zhou, B., Wang, Z., Yang, S., Hao, N., Valks, P., Trautmann, T., and Chen, L.: Remote sensing of $\mathrm{NO}_{2}$ emission from the central urban area of Shanghai (China) using the mobile DOAS technique, J. Geophys. Res., 117, D13305, doi:10.1029/2011JD016983, 2012.

Wang, T., Hendrick, F., Wang, P., Tang, G., Clémer, K., Yu, H., Fayt, C., Hermans, C., Gielen, C., Müller, J.-F., Pinardi, G., Theys, N., Brenot, H., and Van Roozendael, M.: Evaluation of tropospheric $\mathrm{SO}_{2}$ retrieved from MAX-DOAS measurements in Xianghe, China, Atmos. Chem. Phys., 14, 11149-11164, doi:10.5194/acp14-11149-2014, 2014.

Wittrock, F., Oetjen, H., Richter, A., Fietkau, S., Medeke, T., Rozanov, A., and Burrows, J. P.: MAX-DOAS measurements of atmospheric trace gases in Ny-Ålesund - Radiative transfer studies and their application, Atmos. Chem. Phys., 4, 955-966, doi:10.5194/acp-4-955-2004, 2004.

World Health Organization: Review of evidence on health aspects of air pollution (REVIHAAP) - Technical Report, WHO Regional Office for Europe, Copenhagen, Denmark, 302 pp., 2013. 